\title{
Fighting Every Crisis in the Wake of Covid-19: Shifting Grounds for Mobilization among Fridays for Future Protesters in Germany
}

\author{
Beth Gharrity Gardner, PhD \\ University of Copenhagen, \\ Department of Sociology \\ bega@soc.ku.dk
}

Michael Neuber, Dr. phil.

Technical University of Berlin,

Center for Technology and Society (ZTG),

neuber@campus.tu-berlin.de

\begin{abstract}
In upending much of what is usually taken for granted about politics in everyday life, the Covid-19 pandemic is re-animating several puzzles in the study of protest participation. Here we conduct a case study of Fridays for Future (FFF) Global Climate Strike mobilization in Berlin to shed light on the profile of activists who sustained protest mobilization in pandemic contexts. Comparing data from field surveys of protesters at the September 2020 Global Climate Strike with data collected at the pre-pandemic strikes in September and November 2019, we examine the profile of FFF demonstrators along multiple dimensions, including socio-demographics, motivations, political engagement, and institutional trust. Our preliminary results suggest that younger, more politically engaged, and less politically-cynical climate activists joined the street protest under pandemic conditions. Beyond the large turnout of the already-committed, findings also suggest that protesters were more confident in the ability of action and policy to make a difference with climate change but also galvanized by the loss of attention to the issue in the wake of Covid-19.
\end{abstract}

Acknowledgments:

The authors thank the Heinrich-Böll-Stiftung for financially supporting the September 2020 protest survey data collection and the survey team members who helped us systematically conduct the data collection at each of the three global climate strike events in Berlin. 
(C) Authors 2021

Open Access This report is distributed under the terms of the Creative Commons AttributionNonCommercial 4.0 International License (http://creativecommons.org/licenses/by-nc/4.0/), which permits non-commercial re-use, distribution, and reproduction in any medium, provided you give appropriate credit to the original author(s) and the source, provide a link to the Creative Commons license, and indicate if changes were made.

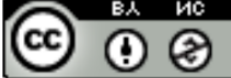

\section{Citing this report}

Gardner, Beth G., and Michael Neuber. 2021. "Fighting Every Crisis in the Wake of Covid19: Shifting Grounds for Mobilization Among Fridays for Future Protesters in Germany." OSF Preprints. July 24. doi:10.31219/osf.io/rsy92. 
The Covid-19 pandemic arose on the heels of a year marked by the revitalization of global climate justice mobilization and mounting attention to the severe threats of the climate crisis. As part of the new wave of youth-led climate justice campaigns that emerged in late-2018, including the US-based "Sunrisers" and Extinction Rebellion, the international Fridays for Future movement coordinated hundreds of simultaneous protest actions around the world in 2019 (Almeida 2019). The meteoric rise and expansion of Fridays for Future beyond school students and beyond Europe over 2019 is well-evidenced (e.g., Chase-Dunn \& Almeida 2020; de Moor, De Vydt, Uba \& Wahlström 2020a; de Moor et al. 2020b; Walström et al. 2019). Although preliminary research suggests that the pandemic dampened the momentum of protest movements internationally (e.g. Metternich 2020), including Fridays for Future (Neuber 2021), empirical research into the impact of pandemic contexts on protest participation dynamics remains scarce. This report focuses on the Fridays for Future (FFF) movements' orchestration of street protests both before and after the onset of the Covid-19 pandemic in Germany.

Employing original protest survey data from three Global Climate Strike (GCS) events in Berlin, Germany, we investigate the impact of pandemic contexts on FFF demographical and attitudinal protest participants. Specifically, we compare the profile of FFF protesters at the pre-pandemic GCS in September and November 2019 with the profile from the first GCS to occur in pandemic contexts on September $25^{\text {th }}, 2020$. While our analysis is mainly descriptive, it sheds initial light on how pandemic contexts impacted the configuration of factors underlying FFF protest participation.

Our protest survey methodology follows the cross-nationally coordinated field surveys on GCS events that took place in March and September 2019 (see de Moor et al. 2020b; Wahlström et al. 2019). This recent research on FFF GCS protests suggests the slices of survey data presented here are pertinent to understanding features of the broader movement. Mainly, the evolving participant base of the FFF movement in Germany is fairly consistent with patterns at the transnational level (see also Kocyba, Neuber, \& Gardner 2020). Berlin has also proven to be a movement stronghold, with 185,000 demonstrators at the large September 2019 GCS (Gardner \& Neuber 2020; Neuber \& Gardner 2020). In pandemic contexts, the evolving profile of FFF protesters in Berlin is likely to be particularly relevant to understanding FFF mobilization in other European metropoles with strong prior FFF protest participation and relatively low Covid-19 infection or mortality rates in September of 2020.

Although we emphasize results where the characteristics of GCS protest participants shifted after the onset of the pandemic, this report is structured along lines similar to the previously coordinated country reports in order to facilitate an ongoing research synthesis. The first section offers some background on the movement's emergence and trajectory and situates GCS events in Berlin within national and pandemic contexts. Next, the protest survey methodology is briefly outlined, with an emphasis on modifications made for the field survey collection during the pandemic. The third section compares results on the demographic composition of protesters at the September 2020 event with those from the September and November events of 2019. Building on this baseline demographic profile, the following sections, Sections 4-6, compare results from several survey items on political behaviors and attitudes over time and, where relevant, by age cohort (with "youths" operationalized as participants under 26 years old and "adults" as those 26 years or older). This is followed by a section on items most directly related to the Covid-19 pandemic. We conclude the report by reviewing key findings. 


\section{The Trajectory of Fridays for Future}

The Fridays For Future (FFF) movement's international wave of protest over 2019 can be traced to the late summer of 2018 when [then 15-year-old] Greta Thunberg launched her lone school strike for climate on the steps of the Swedish national parliament (and the \#FridaysforFuture hashtag) (Thunberg 2019). The movement quickly gained momentum as infrastructures and repertoires of schools, school strikes, and decentralized forms of online activism combined with those of the existing transnational climate justice movement, especially the international protests surrounding UN Climate Summits since the early 2000s (Almeida 2019; de Moor et al. 2020a). Weekly student "school strikes" under the banner of Fridays for Future proliferated across Sweden to other European cities and ultimately expanded into four internationally-coordinated days of action known as 'Global Climate Strikes' (GCS). Little more than a year after Thunberg's strike for climate, and following an explicit call for adults to join the FFF movement, around seven million people in 163 countries worldwide took to the streets demanding immediate political action on climate change at third GCS in September 2019 (de Moor et al. 2020b). Within a similarly short time frame, Thunberg was giving numerous speeches before politicians and economic elites on their own stages (such as at the United Nations and the World Economic Forum).

A number of the movement's features are notable, including its rapid ascension, the continuity of school students and young women as key leaders and participants, and its international expansion to include greater representation from the Global South and older age groups. In relation to the longstanding global climate justice movement, the number and scale of FFF's protest actions around the world hadn't been seen since peaks in 2014 and 2015 (Almeida 2019). In addition to helping to revitalize mass street protest tactics and youth participation in activism, the movement's importance rests on advancing policy demands that blend climate science with climate justice and directing them at state actors. The FFF movement stands out for employing non-institutional forms of action (both on and offline) to engage on the institutional front of national policy (see Chase-Dunn \& Almeida 2020; de Moor et al. 2020a; Gardner \& Neuber 2020).

Critical engagement with international agencies and agreements is also evident in movement goals and claims-making. Pressuring authorities to adhere to the 2016 Paris Agreement and enact policies addressing catastrophic climate change and the fossil fuel industry is a unifying movement goal. This includes demanding approaches that will be more forcefully enshrined in explicit, enforceable law. Accordingly, FFF framing or claims-making, such as "unite behind the sciences" or "no degree further," reflect alignment with the Agreement as well as the mounting evidence released by the Intergovernmental Panel on Climate Change on the intensification of climate change impacts (IPCC 2018). Moreover, in broadly asserting that the global climate crisis must be addressed through environmental policies that are not only anchored in sound scientific evidence, but also socially responsible and ecologically just, the youth-led FFF movement highlights intergenerational justice. Within this framework, FFF activism is foregrounding the importance of younger generations in bolstering the authority of scientific and democratic institutions, while continuing to demand that institutional arrangements better address intersectional and international inequalities.

After the WHO declared the COVID-19 outbreak a pandemic on March 11th, 2020, countries gradually began implementing various restrictions to contain the spread of the novel coronavirus. As a result, FFF protest activities dropped sharply in the first half of 2020 and remained on comparatively low levels until the end of the year. Even though an analysis of the 
movement's online records indicates a slight upward trend in protest activity related to the September 2020 GCS, average participant numbers at the events point to the pandemic's dampening effects (Neuber 2021). This cross-national trajectory is largely echoed in the German context.

Germany entered a high level of "lockdown" by late-March 2020 - including restrictions on civic activities and gatherings of people from more than two households, the relocation of work to the home, the suspension of business at bars and cafes, and social distancing guidelines. Public opinion surveys pointing to renewed trust in government suggest that negative reactions to extensive restrictions early in the crisis were tempered by the relatively low numbers of COVID-related deaths (e.g., Schumacher \& Fagan 2020; Vehrkamp \& Merkel 2020). Although small demonstrations against curbs on public life began taking place weekly in Berlin as early as April, ${ }^{1}$ pandemic restrictions were embraced for the most part by established, progressive movement groups like FFF.

Observing pandemic-related risks, safety recommendations, and restrictions, FFF abandoned plans to hold mass GCS events coinciding with Earth Day (April 22, 2020). As in other countries discouraging social gatherings, organizers in Germany moved activities online for the April 24th strike (with the hashtag mottos \#FightEveryCrisis and \#NetzStreikFürsKlima). Despite ramping up its online mobilization efforts in the Spring, the movement did not completely abandon offline action repertoires. Organizers in Berlin, for example, collected 10,000 protest signs from supporters and placed them in front of the Reichstag parliament building. They also set up a video stream on YouTube, broadcasting the installation of the signs as well as speeches by activists.

With infection rates on the decline over the warmer summer months, Germany witnessed larger protests against shifting pandemic restrictions. This included the so-called corona demonstration of around 38,000 people in Berlin in late August, which notoriously ended with an attempted occupation of the Reichstag by some of the protesters. ${ }^{2}$ By contrast, it was not until September 25th that FFF coordinated a return to the streets for a GCS protest in locations where Covid-19 restrictions were eased. At this time, the COVID-19 ordinance in Berlin required the wearing of mouth and nose protection for gatherings of more than 100 participants, a minimum distance of 1.5 meters between the attendees, and chanting was forbidden. ${ }^{3}$ Protest organizers were required to provide the authorities with a tailored concept detailing how they intended to comply with these regulations. However, they were not required to limit participant numbers.

Given pandemic constraints, it isn't shocking that the FFF protest on September $25^{\text {th }}, 2020$ was the smallest GCS in Berlin to date (Figure 1). With an estimated 16,000 participants at the Brandenburg Gate over the day, the turnout was around one-tenth of the number estimated at the GCS a year earlier $(\sim 185,000)$, and around one-fourth of the over 52,000 estimated

\footnotetext{
${ }^{1}$ https://www.thelocal.de/20200501/german-extremists-plan-may-1st-protests-against-covid-19-measures

2 https://www.bbc.com/news/world-europe-53959552; https://web.archive.org/web/20200924031019/https://www.berlin.de/corona/massnahmen /verordnung/; accessed on February 24, 2021. - Sixth Ordinance Amending the SARS-CoV-2 Infection Protection Ordinance by the Senate of Berlin.

${ }^{3}$ In Germany, the constitutional right of assembly became the subject of contention. With its focus on the primacy of the freedom of assembly, German law does not provide explicit regulations in the case of a pandemic. Furthermore, the federal jurisdiction grants the Bundesländer substantial leeway in the specific implementation of the fundamental right. Not least as a result of this regulatory vacuum and diversity, there have been numerous court decisions in the matter of the Corona protests, in which the restrictions on the demonstrations were at stake.
} 
protesters at the GCS in November of 2019 (Neuber \& Gardner 2020; Sommer, Hauns, Gardner, Neuber, \& Rucht 2020). Dense crowd prevention was also clearly part of how the movement adapted the GCS arrangements to pandemic contexts and restrictions. For instance, multiple street processions - including a demonstration via bicycle organized by environmental associations and a group of red-robed Extinction Rebellion protesters - started at different locations in the city, crossed paths, and converged around the Brandenberg Gate during the event.

Moreover, rather than the usual demonstration march, FFF held a sit-in on the Straße-des-17Juni. Pulling this off required placing thousands of markers on the street following official distancing guidelines before the event as well as stewards monitoring these distances on the day of the event. Notably, organizers managed to further recast or adapt the traditional civil disobedience tactic of the sit-in for pandemic contexts. And although FFF stewards were deployed throughout the day to ensure compliance with the city's rules, the vast majority of participants adhered to social distancing and wore masks. Beyond demonstrating their commitment to health and scientific expertise through orchestrating the event to observe public safety, by mobilizing the September 25th GCS under the slogan and hashtag "\#NoDegreeFurther!" organizers also stayed true to framing movement demands in line with the scientifically-grounded policy orientation of the Paris Agreement and IPCC report - i.e., the need to ensure no further increase global warming than 1.5 degrees Celsius.

\section{Figure 1: Participant Numbers at the Global Climate Strikes in Berlin}

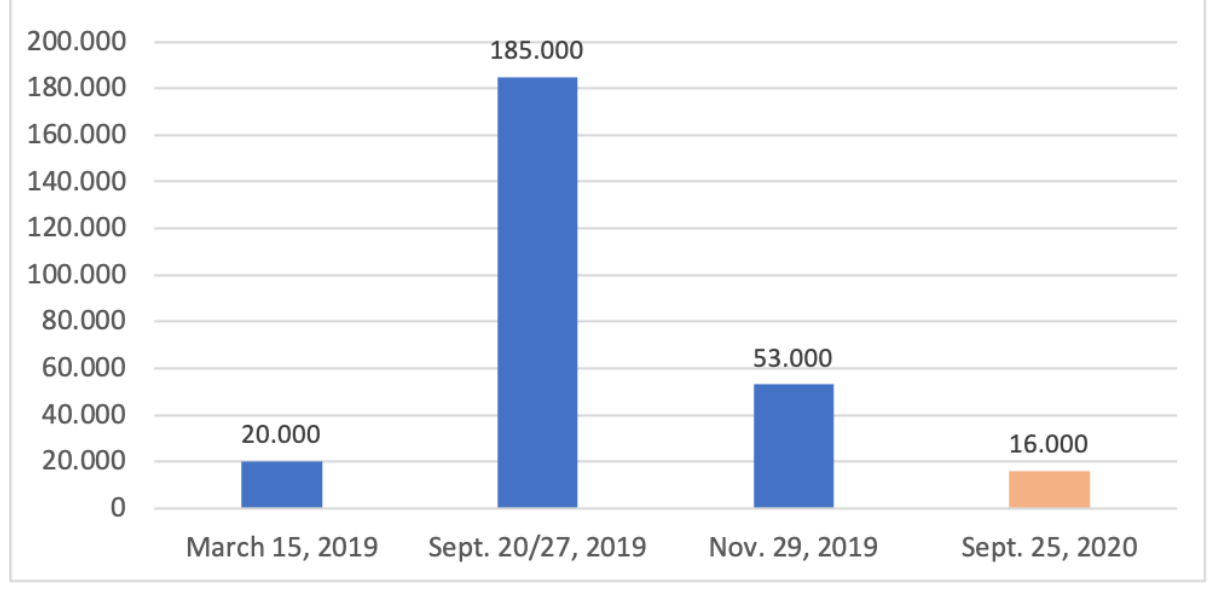

\section{Data and Methods}

Data collection followed the crowd survey method developed by van Aelst and Walgrave (2001), and established in the international research project Caught in the Act of Protest: Contextualizing Contestation (CCC) (Van Steklenburg et al. 2012; Walgrave, Wouters, Ketelaars 2016; see also Fisher et al. 2019). This methodology is designed to ensure the random selection of interview respondents, minimize response biases, and link individual attributes to mobilization contexts in a standardized fashion. The CCC approach was moderately adapted to coordinate data collection at the March 15 GCS in 13 European cities (Wahlström et al. 2019) and at those that occurred during the 20-27 September 2019 week of action in 19 cities across four continents (de Moor et al. 2020b). Mainly, face-to-face interviews were combined with flyers linking to an online survey rather than with printed, mail-in surveys. 
Before turning to distinct features of the methods employed during the pandemic GCS in Berlin and the data we analyze, the main contours of the CCC methodology merit a brief discussion. Tailored for comparative protest research, survey teams at different protest events follow a systematic counting and sector strategy for randomly selecting participants from the full complement of demonstrators. Selected respondents are given a flyer with basic information about the research, a web address and QR-code to the online survey, and a unique identification number. Every fifth respondent is interviewed face-to-face, on-the-spot, using a handful of items from the longer survey. Because almost all respondents agree to the short interview, the basic interview data allows us to assess potential non-response bias to the longer online survey (Van Stekelenburg et al. 2012: 258). The online survey consists of several common sociodemographic and political attitude and behavior questions, including items about reasons for protesting, forms of political engagement, and confidence in various institutions. Thus, multiple items are consistent with general social surveys and political mobilization writ large.

As these data collection methods at the FFF demonstrations in 2019 are detailed elsewhere (c.f. de Moor et al. 2020b), ${ }^{4}$ we turn now to discussing those features unique to the GCS in pandemic contexts. The baseline methodology was primarily adapted to strictly observe official safety requirements and health recommendations. Several procedures were introduced to reduce potential risks to those distributing the survey flyers as part of our survey team. These included informing potential team members about the risks, exclusion criteria (e.g., health conditions, feeling unwell on the day of the event), how to use the provided protective gear (e.g., N95 masks, visors, gloves, disinfectant), and the safety protocols required of them (e.g., for transport to and from the event, observing social distance rules). Additionally, we introduced a handful of new questions to get at protesters' perceptions of the pandemic - such as the influence of the pandemic on their decision to protest, views on the government's pandemicrelated restrictions, and about prioritizing the pandemic in relation to climate issues.

Although pandemic conditions led us to adjust some of the CCC-based data collection techniques, it was possible to maintain the required minimum distance of 1.5 meters and still adhere to the randomized respondent selection protocols. A few small changes made this feasible. Among them, we printed larger flyers to accommodate a more detailed invitation to participate in the survey, instructions, as well as a larger QR code link to the online survey so that participants could take a photograph (at-distance) with their cellphone. The nature of the GCS event in Berlin was also fairly conducive to the participant selection protocols. Insofar as it was smaller, more dispersed, and organized to fit with official guidelines, the event encouraged the observance of social distance in ways that reduced the crowd density and made it easier to follow the selection procedures in many cases. For example, the sit-in was organized in the shape of a matrix with large distances between the individual participants (see Figure 2)..$^{5}$

\footnotetext{
${ }^{4}$ Of note, pre-pandemic FFF data collection results suggest the data are likely to underrepresent protesters under 14 years old and may underrepresent the less internet-savvy. The latter reflects potential issues of access to the online survey, although internet penetration is very high in Germany. The former reflects accordance with national legal and ethics regulations, only protestors older than 13 years of age are invited to participate in the survey. Such limitations are common in social scientific research, including CCC protest research. However, as people under the age of 14 comprise a particularly relevant segment of participants in Global Climate Strikes, we encourage caution when interpreting our results.

${ }^{5} \mathrm{We}$ also find that nearly $30 \%$ of protesters reported attending the event alone - a larger share than ever before.
} 


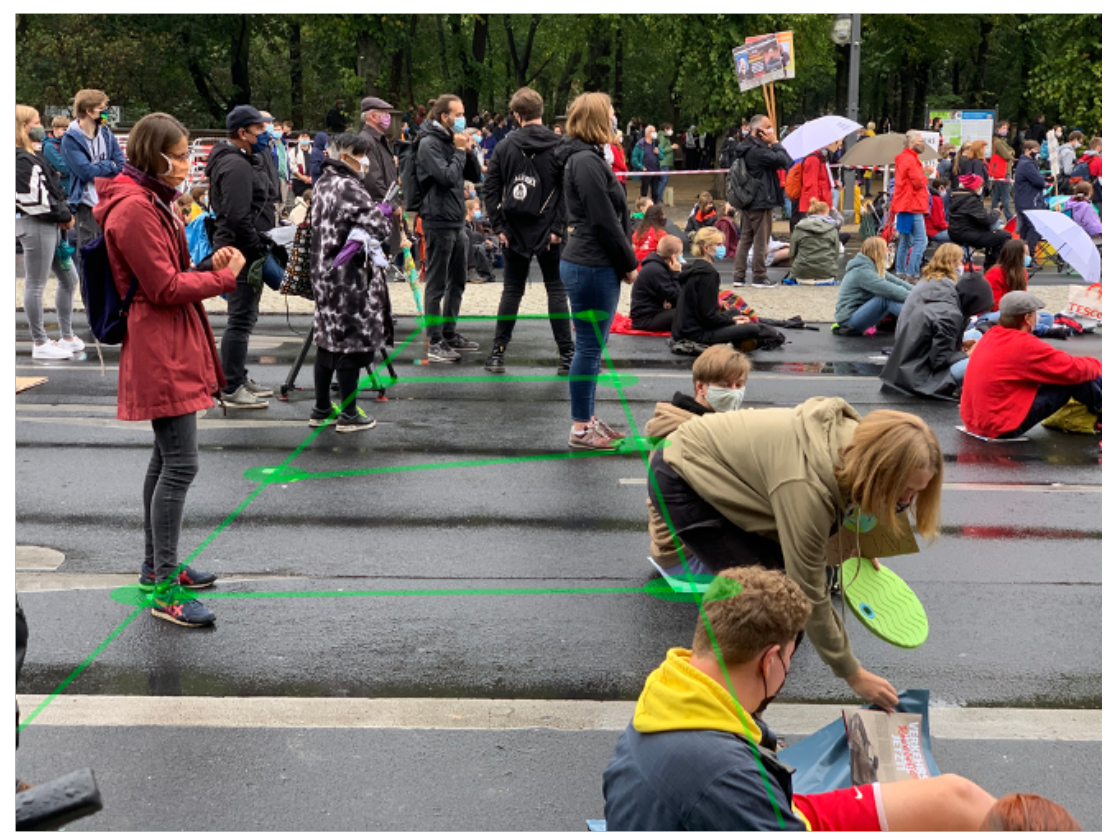

Critically, though, we decided that conducting the short, face-to-face interviews with every fifth respondent was too risky. Instead of the short interviews, survey team members conducted systematic visual assessments of the protesters they approached to participate in the survey. ${ }^{6}$ Unfortunately, as we discuss next, this limits the basic interview data used to evaluate nonresponse bias to age and gender.

\section{Data}

We analyze survey results from three demonstrations in Berlin: the September and November GCS of 2019 and the September demonstration in the pandemic circumstances of 2020 (see table 1 below). Respondents are fairly evenly distributed between the three events. According to organizer estimates, about 16,000 people protested in Berlin, and 200,000 across Germany, at the September 25, 2020 GCS in pandemic contexts. ${ }^{7}$ The response rate remained high compared to previous survey waves, ranging from $22 \%$ (November 2019) and 34\% (September 2020). However, we only include surveys that were at least $50 \%$ complete as valid cases in our analysis. We analyze 342 (valid) individual surveys in total, which includes 123 valid surveys from September 2020.

\footnotetext{
${ }^{6}$ In an effort to minimize biased estimates (e.g. Voelkle et al. 2012), survey team members working in pairs were instructed to make a joint assessment, to systematically round the person's age down to the lower decade, and to include any additional notes with their entry into a provided coding-sheet. Despite these considerations, some bias is inevitable and the prevalence of participants wearing masks and social distancing created novel obstacles to age estimation.

${ }^{7}$ https://www.zeit.de/gesellschaft/2020-09/fridays-for-future-klimastreik-klimapolitik-demonstration
} 
Table 1: Survey Response Rates for Global Climate Strikes in Berlin

\begin{tabular}{cccccc}
\hline Date & $\begin{array}{c}\text { GCS } \\
\text { participants (no.)* }\end{array}$ & $\begin{array}{c}\text { Survey invitations } \\
\text { distributed (no.) }\end{array}$ & $\begin{array}{c}\text { Online interviews } \\
\text { (no.) }\end{array}$ & $\begin{array}{c}\text { Response rate } \\
\text { (\%) }\end{array}$ & Valid cases (no.) \\
\hline Sept. 20, 2019 & 185.000 & 433 & 115 & 27 & 114 \\
Nov. 29, 2019 & 53.000 & 509 & 110 & 22 & 105 \\
Sept. 25, 2020 & 16.000 & 467 & 158 & 34 & 123 \\
\hline Total & & $\mathbf{1 . 4 0 9}$ & $\mathbf{3 8 3}$ & & $\mathbf{3 4 2}$ \\
\hline
\end{tabular}

*averaging the estimates of FFF organizers and police.

For the 2019 survey data, we found no statistically significant differences between the sample of online survey results and the sample of respondents who gave face-to-face interviews at the events (e.g., on items for gender, age, political interest, education, satisfaction with democracy, prior protest participation). To establish the representativeness of our survey data from September 2020, we compare the visual assessments of age and gender by survey team members with those from the sample of people who completed the online survey. We found no significant difference for gender. But there was a significant difference in the age distribution of the two samples. The visual data suggests a higher share of younger demonstrators than the share that completed any or at least $50 \%$ of the survey. Considering work on bias in visual age estimation and the approximation strategy of rounding down during participant age estimation, ${ }^{8}$ we interpret this difference as capturing a systematic underestimation of participant age by survey team members rather than an actual pattern in non-response bias. With these caveats in mind, we are reasonably confident that our data offer a representative picture of participants at each of the protests surveyed.

More broadly, the results from our Global Climate Strike (GCS) surveys in Berlin cannot be considered representative of all FFF protesters in Germany or internationally. Nevertheless, prior research suggests they do get an important cross-section of those mobilized at FFF global climate actions in Germany (e.g. Neuber \& Gardner 2020; Sommer, Haunss, Gardner, Neuber, \& Rucht 2020), and may provide insights into FFF protest dynamics in European and North American metropoles (e.g., de Moor et al. 2020b; Neuber, Kocyba, \& Gardner 2020). Comparing our survey results from the most recent September 2020 GCS event with those from the two most temporally proximate GCS of 2019 can speak to changes in the composition and views of FFF protest participants before and after the onset of the pandemic that is likely to be relevant to the broader movement.

\section{Demographic profile}

The socio-demographic profile of FFF protesters has garnered a fair share of attention from journalists and scholars alike. This broad-strokes profile tends to be that of a school-aged female - a profile easily associated with movement leader Greta Thunberg. Cross-national GCS protest survey research has lent credence to this image, especially as the inclusion of younger students contributes to the movement's novelty. Of course, it's also important not to overstate the demographic uniformity of movement participants. The heterogeneity of participants that comprise movements is precisely what protest surveys often help to reveal. And from cross-

\footnotetext{
${ }^{8}$ According to Voelkle et al. (2012), people estimate the age of peers more accurately than that of other age groups. They also found that the "age of older faces was more difficult to estimate than the age of younger faces." With this in mind, it is likely that our survey team - comprised of people their $20 \mathrm{~s}$ - underestimated the age of potential respondents. Nevertheless, it remains possible that our data from the GCS in pandemic contexts underrepresents younger participants.
} 
national surveys of FFF protesters, we know that the age profile of FFF's participant base at GCS events has proven dynamic over time and place, and that the gender distribution at GCS events has been fairly balanced on average, with women more often outnumbering men among younger participants (e.g., de Moor et al. 2020b; Neuber, Kocyba, \& Gardner 2020). Here, we focus on examining where the demographic composition of FFF protesters in terms of age, gender, education, and subjective class identification shifted in any pronounced ways after the onset of the Covid-19 pandemic in Berlin.

Compared to GCS events prior to the pandemic, our survey results from September 2020 suggest the age make-up of protesters was the most substantial shift in the demographic profile of participants. Across the events, the gender distribution remained relatively balanced between male and female (47\% and 52\% respectively, on average), education levels remain high and similarly distributed, and strong majorities of protesters identify as being part of the middle or upper class ( $\sim 70 \%$ at each event). By contrast, as shown in Figure 3.1, the mean and median age of participants declined notably under pandemic conditions.

Figure 3.1: Mean and Median Age

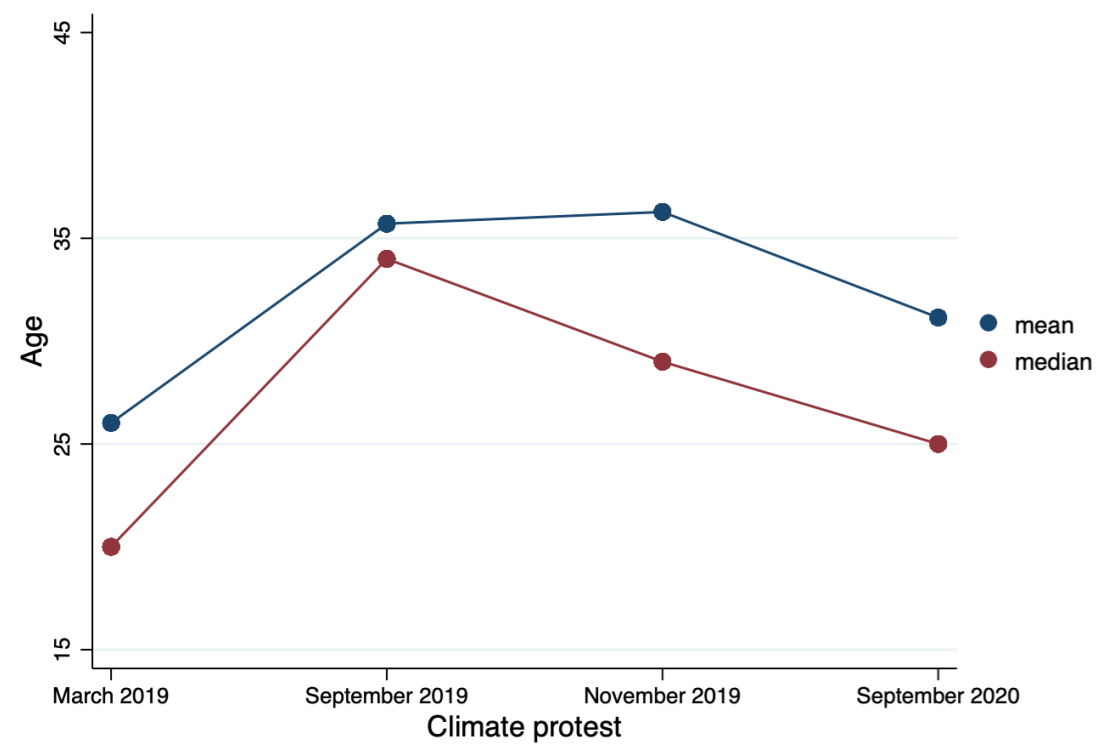

As previously demonstrated (Neuber \& Gardner 2020), the movement's participant base expanded to include a much larger share of older participants at the \#allesfürklima GCS on September 20, 2019. At this demonstration, the average age of protesters was significantly greater than their March predecessors in Berlin (up from 26 to 36; $p<.001$ ), and in the vast majority of the other cities where GCS events were surveyed (e.g., de Moor et al. 2020b; Gardner \& Neuber 2020). ${ }^{9}$ The age trend from subsequent events points to a partial 'rejuvenation' of the movement in Berlin. At the November strike, the mean age remained stable at 36 but the median age dropped from 34 to 29. At the pandemic GCS in September 2020 , we find a further drop in the median age to 27 years as well as a small decline in the mean age to 33 years.

This shift is further evidenced by breaking age down into different groups (see Figure 3.2). Notably, the share of respondents in the 36 to 45 -year-old age group shrunk by $18 \%$ from the

\footnotetext{
${ }^{9}$ In Germany, the largest respondent age cohort was 14-19 years old (52\%) in March and 20-35 (37\%) in September.
} 
large \#AllesfürKlima GCS event of September 2019 to the GCS in pandemic contexts a year later. Further, the share of participants under 36 years of age increased by $18 \%$ between the two events (from 54\% to 72\%). Pandemic-related factors, such as increased child care due to school closures as well as the heightened risks posed by the novel coronavirus to older people and those aware of pre-existing health conditions, likely contributed to the dominance of participants under 36 years of age. This speaks to the possibility that the pandemic amplified the role of "biographical availability" in GCS participation (McAdam 1986).

Figure 3.2: Age Distribution

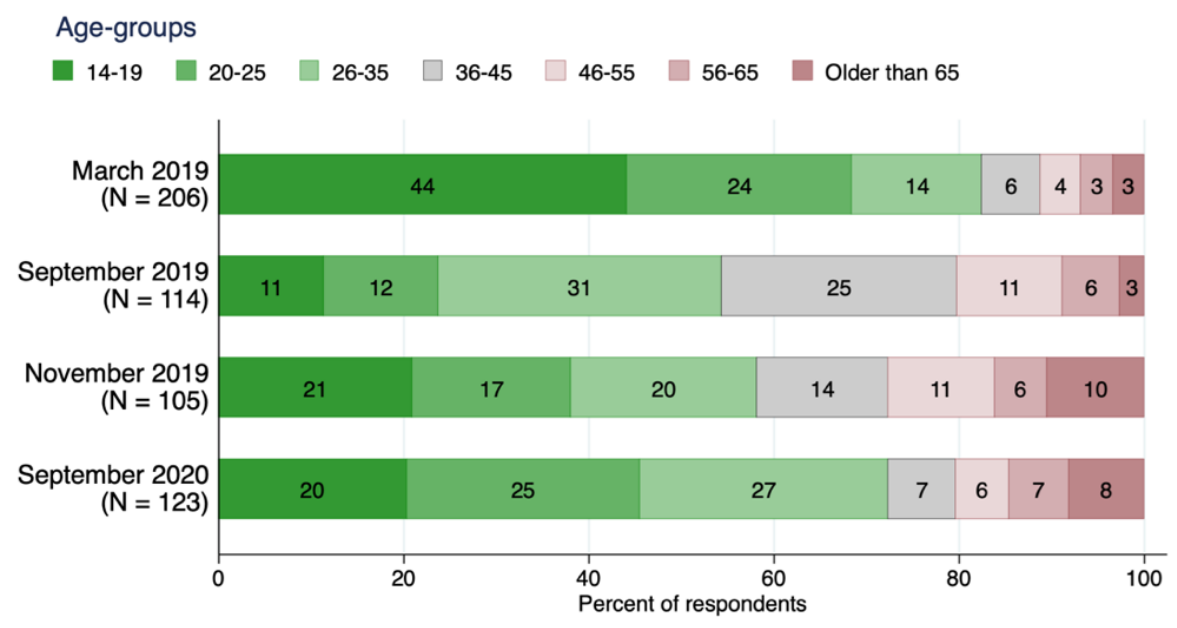

With students and other groups joining the mainly pupil-led protests over the course of 2019, the FFF appears to have evolved into a broader movement of students and young professionals. This continues to be the case despite the younger average age of FFF protesters at the pandemic GCS (compared to September and November 2019). While the number of pupils at the GCS events decreased slightly between November 2019 and September 2020 (from 15\% to 13\%, not shown), the number of university students rose by 7\%: from $28 \%$ in November 2019 to $35 \%$ in September 2020. Additionally, the proportion of protesters who are neither students nor pupils has steadily declined in Berlin since September 2019 (71\%). But this group still accounts for 53\% of protesters at the GCS in September 2020. With 26- to 35-year-olds as the largest age group (32\%), young professionals play an important role in this segment of FFF protesters (results available from authors upon request).

To analyze distinctions between younger and older generations of protesters in this report, we routinely cluster survey respondents into "youths" up to 25 years old and "adults" 26 years or older. This categorization is congruent with the previous collaborative work and publications using GCS protest surveys (c.f. de Moor et al. 2020b). Moreover, the categories are analytically useful for considering different generational cohorts. Our classification of "youths" approximates "Generation Z" (people born after 1996), the cohort after "Millennials" (people born between 1981 and 1996) (e.g., Dimok 2019; Milkman 2017). That is, without a definitive threshold for distinguishing generations, the classification focused on bounding the political socialization period of young people - i.e., the formative years in which conditions of prosperity versus hardship and/or the development of political attitudes and behavioral habits are argued to have lasting effects (e.g., Inglehart 1977; Milkman 2017). Figure 3.3 shows the distribution of the two age cohorts over time in Berlin. 
Figure 3.3: Generational Cohorts ('Youths' and 'Adults')

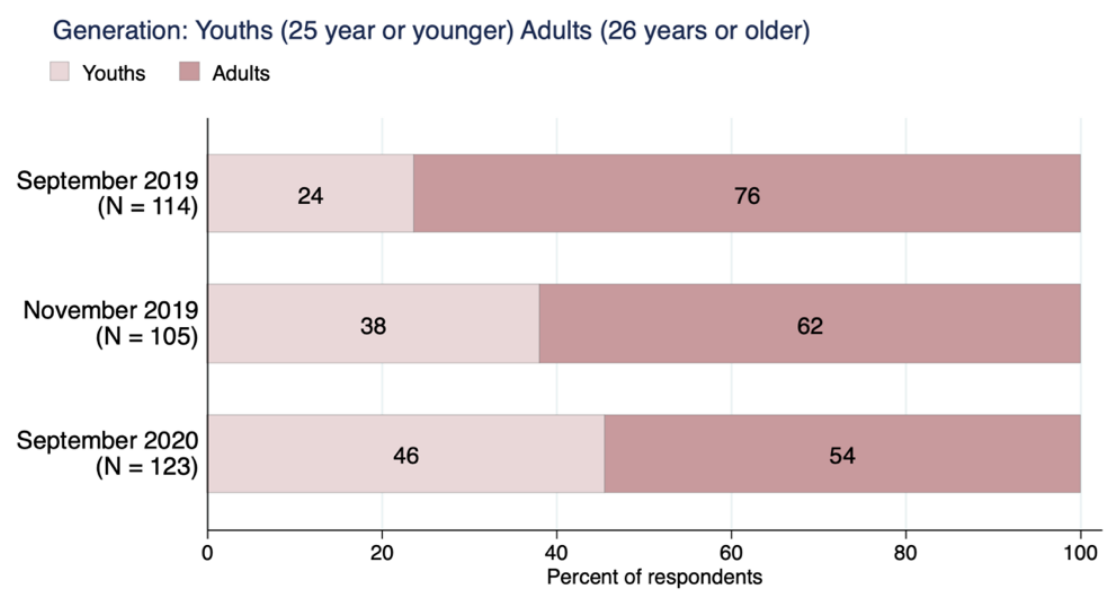

Having made this age distinction, Figure 3.4 illustrates the fairly stable gender balance across the events. At the pandemic GCS in September 2020, we can see that adult male protesters slightly outnumbered women for the first time. However, with female protesters in the majority among youth, the public image of FFF as a movement spearheaded by young women remained largely accurate across the GCS events in Berlin, including the first GCS in pandemic contexts.

\section{Figure 3.4: Gender by Generational Cohorts}

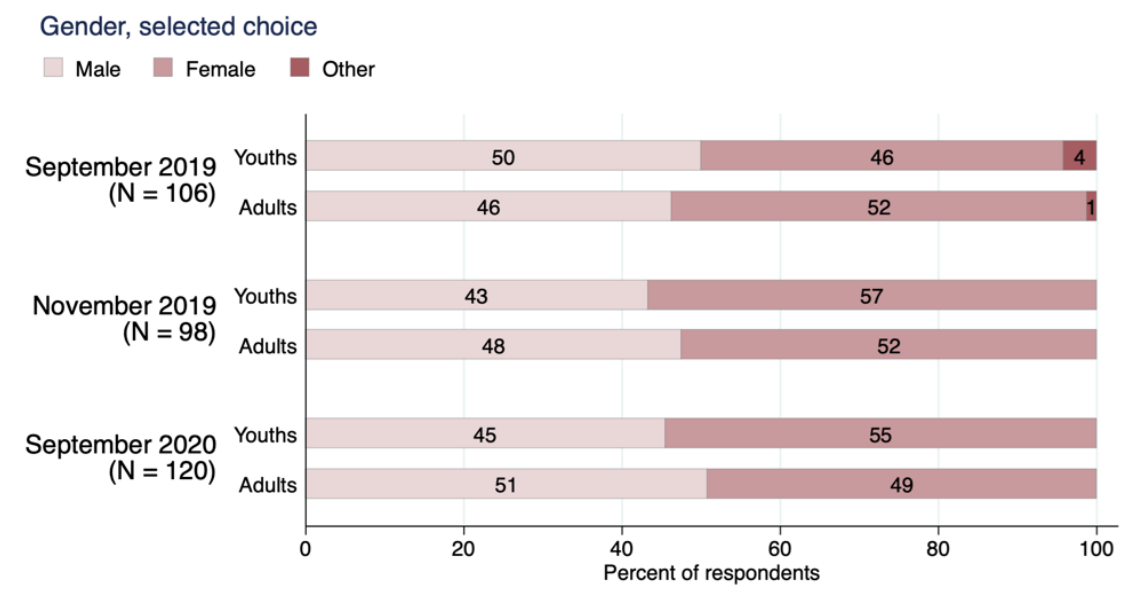

\section{Engagement profile}

There are multiple pathways to protest participation, many of which are anchored in people's experiences with participatory civics. Among these, research shows that engaging in collective action like street protest can generate or reinforce the solidarity, commitment, and basic familiarity with protesting that are likely to spur future activism along similar lines (e.g., Collins 2004; Saunders et al. 2012; Van Stekelenberg \& Klandermans 2013). Consistent with this expectation, we find the majority of participants in both generational cohorts and across the GCS events had previously taken part in some kind of demonstration in their lifetime (not shown). 
Although adults have more prior experience with protesting in general (because age tends to be correlated with such experiences), this gap is far less consistent - even absent at times when we compare the two cohorts' protest experience in just the past year. As Figure 4.1 shows, a smaller percentage of youth (14-25 years old) than adult (26+) respondents were protesting for the first time at all three GCS events. Over time, the proportion of first-timers consistently decreased in both age cohorts. Further, we find a greater intensity of protest engagement over the past year among youths - i.e., a larger share of youth protested more than 11 times in the past year than adults at each GCS event.

\section{Figure 4.1 Prior Protest Participation (past 12 months)}

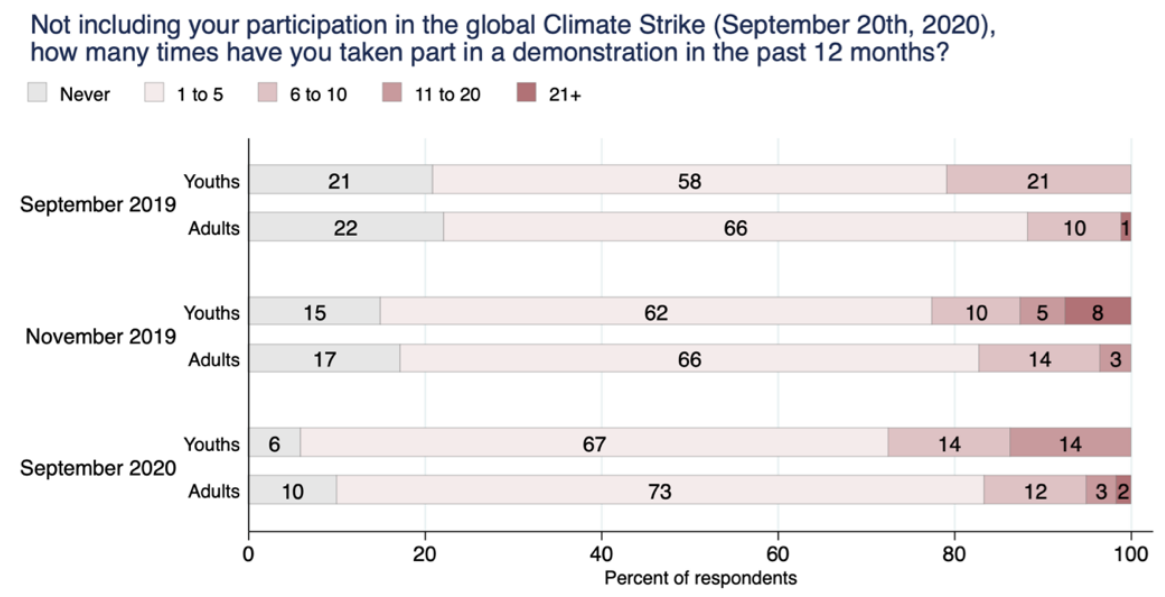

Participation in earlier FFF actions (and protests related to environmental issues) helps to account for these results. We find an overwhelming majority of participants at the GCS in pandemic contexts had previously protested at a GCS event. That is, few were GCS "novices" (see Saunders et al. 2012). As shown in Figure 4.2 the greatest share of respondents reported participating in the large, September 2019 global day of action (69\%), followed by the GCS that took place a month later, in November 2019 (49\%). Of further note, the share of GCS novices at the September 2020 GCS was slightly greater (8\%) compared to the year before (results not shown).

Figure 4.2: Prior Global Climate Strike Participation (from September 2020 GCS)

Did you participate in the demonstration during the Global Climate Strike on ...

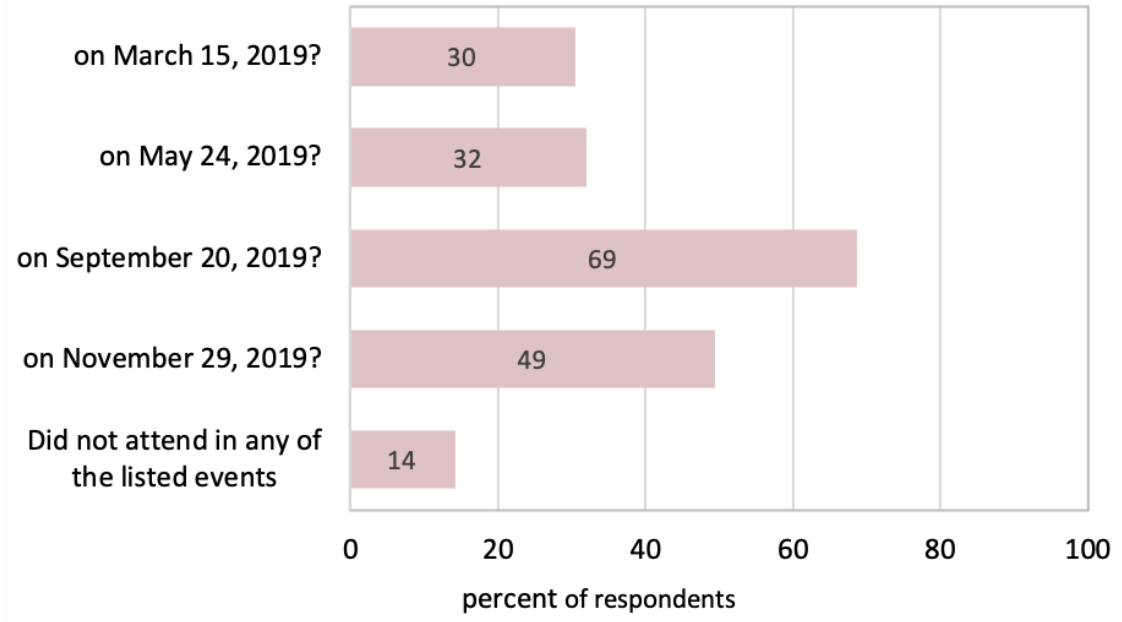


To further unpack these results, we consider FFF protesters' engagement in more "traditional" and less-publicly visible forms of political action over the past 12 months. ${ }^{10}$ These include contacting an elected official, signing petitions, engaging in online political advocacy, and shifting consumption practices to prevent or promote change. Among September 2020 respondents, we find a general pattern of greater engagement across the board. As the survey includes numerous behaviors and the trend is towards greater action over the events, we limit our discussion to items on which responses from the 2020 GCS differed most from the one a year earlier - the pre-pandemic strike of September 20, 2019 (see Figure 4.3).

\section{Figure 4.3: "Traditional" Engagement Patterns}

Have you, in the past 12 months...?

o September $2019 \bigcirc$ November 2019 • September 2020

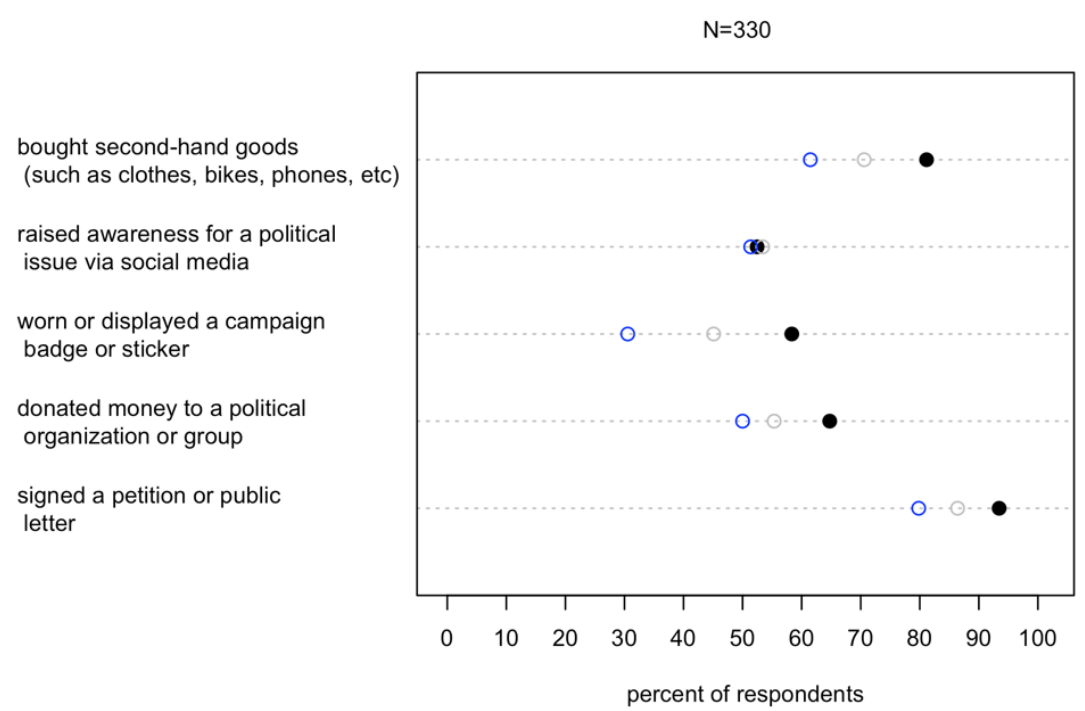

The largest change was a $27 \%$ increase in the share of FFF protesters who reported wearing or displaying a campaign badge or sticker, which was especially high among youths (generational differences not shown). We also find large increases in purchasing second-hand goods (up $20 \%$ ) and donating money to a political organization or group (up 15\%). Here, $87 \%$ of youth protesters and $76 \%$ of adults reported buying second-hand goods, but a higher proportion of adults (70\%) than youths (58\%) reported donating money to a political group. Another notable shift is a $13 \%$ increase in the share of participants who signed a petition in the past year (with no substantial differences between cohorts). We include the results on using social media to raise awareness for a political issue because we find the absence of change here interesting. The share of participants who reported such activity did not increase at the GCS event in pandemic contexts, with around $50 \%$ of youth and adult protesters.

Embeddedness in civil society groups, such as volunteering for a political party or environmental organization, often goes hand in hand with conventional forms of political action just discussed as well as protesting (e.g., Klandermans, Van der Toorn \& Van Stekelenberg 2008; McAdam 1988; Van Stekelenberg \& Klandermans 2013). Therefore, we also examine FFF protesters' active or passive membership in various types of organizations to shed some light on the potential role of associational embeddedness in channeling people to GCS events. We present results for environmental group membership because the largest shares of protesters consistently report this type of associational involvement across the events.

\footnotetext{
${ }^{10}$ The question wording was: "There are many things people can do to prevent or promote change. Have you, in the past 12 months...?"
} 
At the September GCS, the next largest share of adults reported memberships in charity or humanitarian organizations, whereas sports or cultural groups are nearly tied with environmental ones among youths. Memberships in a political party or its youth organization were low among respondents, which is also consistent with previous GCS findings (c.f. Neuber \& Gardner 2020).

Although environmental group membership did not change dramatically across the three events or within either age cohort, we do observe a shift towards more active membership over time (See Figure 4.4). By age cohort, the proportion of youth respondents holding any type of environmental group membership increased slightly at each event. For example, smaller shares of youth respondents held such memberships in September $(16 \%)$ and November $(24 \%)$ of 2019 than did in September 2020 (31\%), and the share with an active membership approximately doubled at each event (i.e., 4\%; 11\%; 20\%). Further, active memberships increased at each event among respondents in both age cohorts (to $25 \%$ on average at the 2020 GCS).

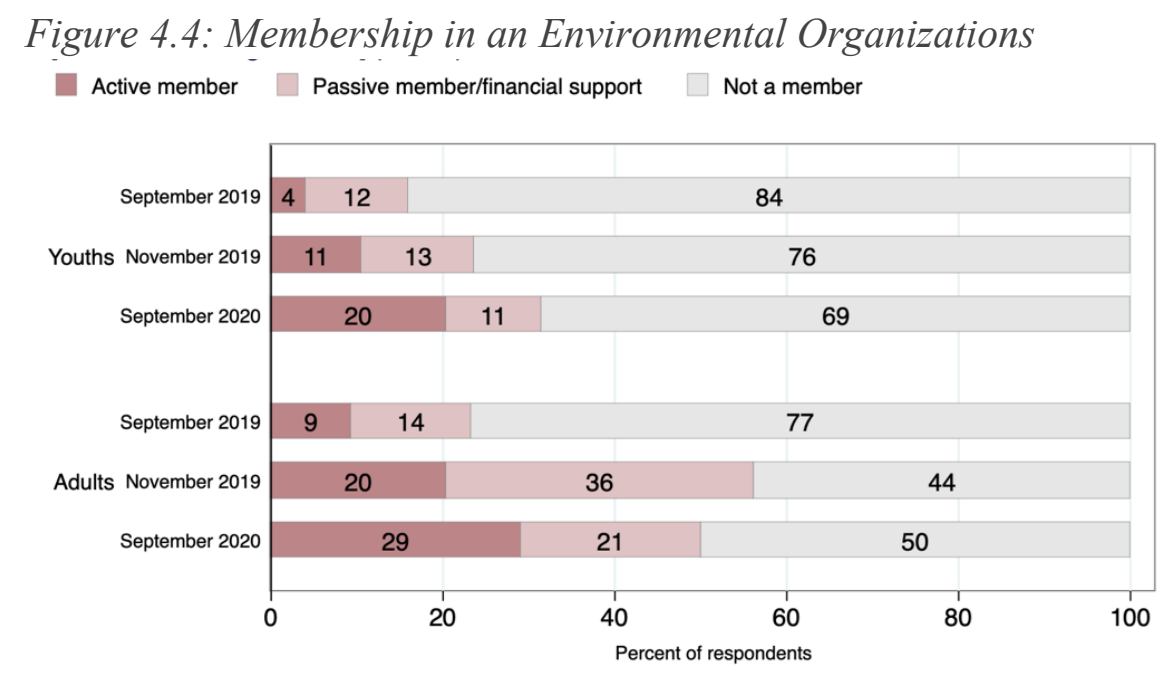

At the GCS in pandemic contexts, the ratios of active to passive members flipped from the previous events. This pattern of increasing depth of associational involvement among participants is easy to overlook at first glance because it is not echoed with greater overall membership among adults. In short, we find a pattern of increasing depth of environmental association involvement among FFF protesters. Taken together, our results indicate that the people who joined the GCS on September 252020 were both more politically active and institutionally embedded than those at prior GCS events.

\section{$5 \quad$ Why did they protest?}

Experience with protest and other forms of participatory civics can all influence people's decisions to join a protest, but they still require us to infer a lot about people's motivations. The literature bridging social psychology with protest participation dynamics underscores the need to understand people's perceptions to understand why they protest (c.f. Van Stekelenberg \& Klandermans 2013). Drawing on this work, this section discusses how participants responded to questions explicitly about their motives for joining the climate strike, their perceptions that individual and collective action can influence policy (i.e., efficacy perceptions), and their feelings when thinking about climate change. 
Both youth and adult participants were highly motivated to protest at the September 2020 GCS in pandemic contexts. As Figure 5.1 illustrates (below), large shares of respondents agreed to hold multiple motivations. The percentage of FFF protesters motivated to raise public awareness stands out for being greater than at the previous events. Similarly, the goal of pressuring politicians to enact a more comprehensive environmental protection policy continued to be a widely-held motivation for joining the September 2020 GCS and was only slightly lower than at the large September 2019 GCS. Along with pressuring politicians and generating public attention, nearly $90 \%$ of the demonstrators on average were motivated to express solidarity and express their views. Joining because someone asked played the least important motivational role overall in participation across the surveyed events.

Figure 5.1: Motivations for Participating

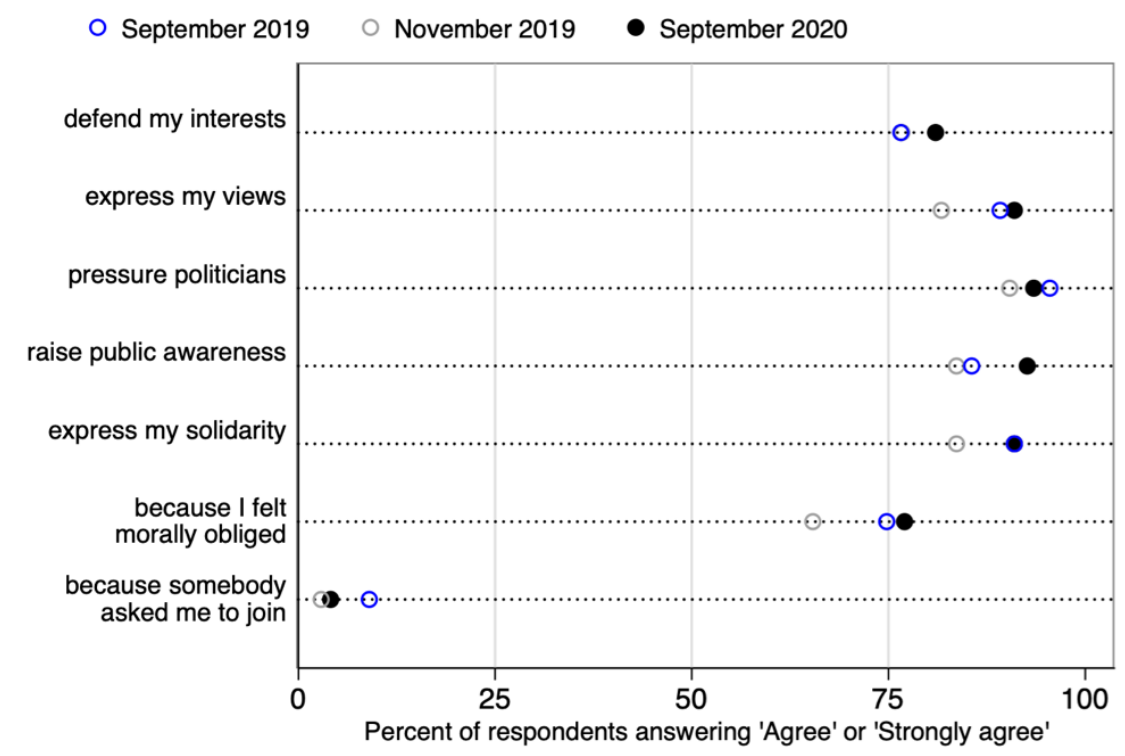

It isn't surprising that we find a more motivated set of participants joined the GCS in pandemic contexts given the greater hurdles to participation. Interpreted alongside the engagement profile findings from the previous section, we suspect that these high motivation scores also reflect the greater turnout among people highly committed to or involved in activism, especially in the FFF and/or broader climate justice movement. To explore this further, we examine protesters' responses to items concerning the impacts of political engagement on policy.

It is widely argued that for people to protest, they need to believe their participation can help to redress their concerns (e.g., McAdam 1988; Gamson \& Meyer 1996; Van Steklenberg \& Klandermans 2004). That is, they need to think their participation matters - that it will be efficacious. To get at these perceptions, we measure efficacy at the individual level by assessing the extent to which respondents agreed with the statement "my participation can have an impact on public policy in this country," and at the collective level, with the statement "organized groups of citizens can have a lot of impact on the public policy in this country."

As shown in Figures 5.2 and 5.3, respondents consistently felt more effective collectively than individually. Among adult protesters, agreement on both efficacy measures was highest at the GCS in pandemic contexts. Among youths, the share of agreement was similarly high at the two September GCS events, but the strength of agreement on both items was greater at the prepandemic GCS. We can also see from the figures that the distributions were nearly identical among youths and adults at the September 2020 strike. 
Figure 5.2: Personal Efficacy

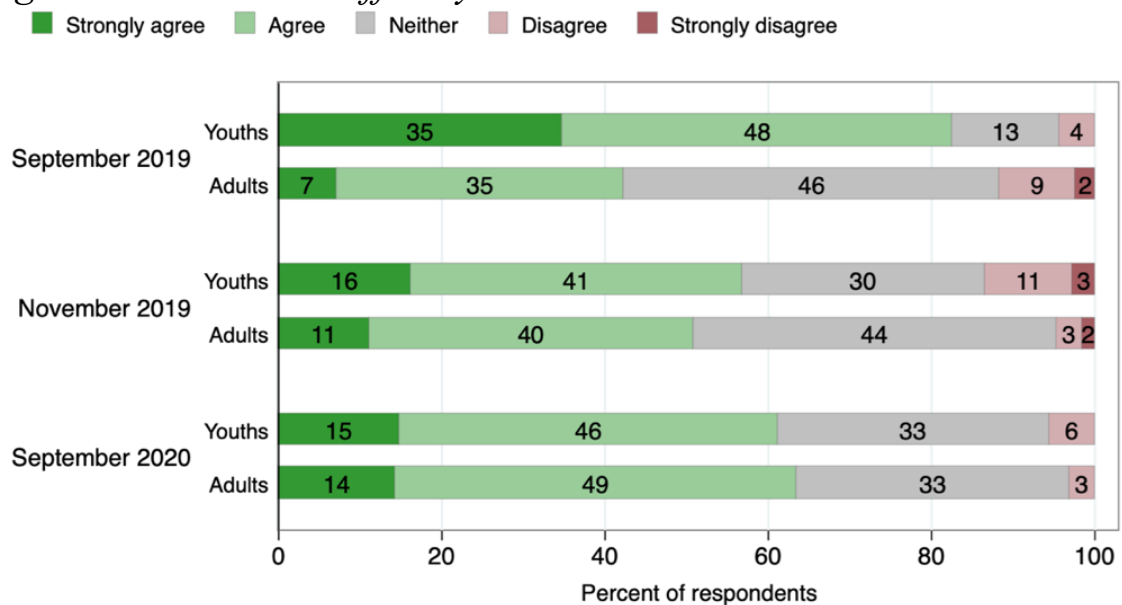

Figure 5.3: Collective Efficacy

[Organized groups of citizens can have a lot of impact on public policies in this.]

Strongly agree $\square$ Agree $\square$ Neither $\square$ Disagree $\square$ Strongly disagree

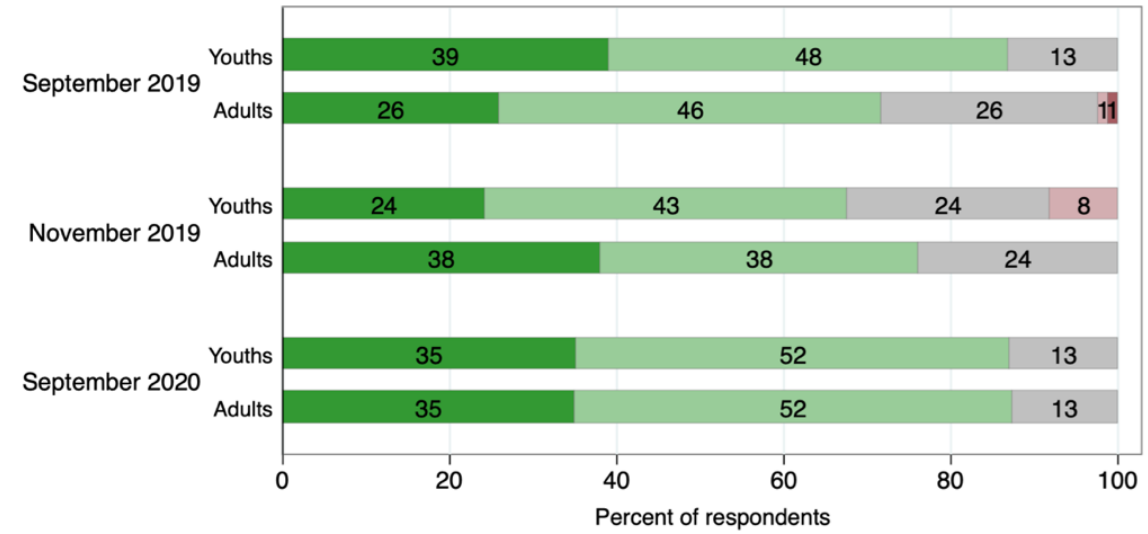

Of course, the cognitive and emotional components of motivation for engaging in protest cannot be easily disentangled. Movement scholars recognize that emotions can be mobilizing as well as demobilizing and that they can amplify people's motivations for protesting (e.g., Goodwin, Jasper, \& Polletta 2009; Jasper 2014; Shultziner 2013; Van Stekelenberg \& Klandermans 2013). Strong emotions, especially indignation about a particular conflict or issue, are considered to be decisive drivers towards expressions of political dissent. Our survey results point to four dominant emotions that can each be closely linked to indignation. Across the GCS events, a large majority of participants felt anxious or worried, and angry or frustrated when thinking about climate change (see Figure 5.4). At the GCS in pandemic contexts, the shares of respondents reporting feelings of anxiety and anger reached all-time highs. 


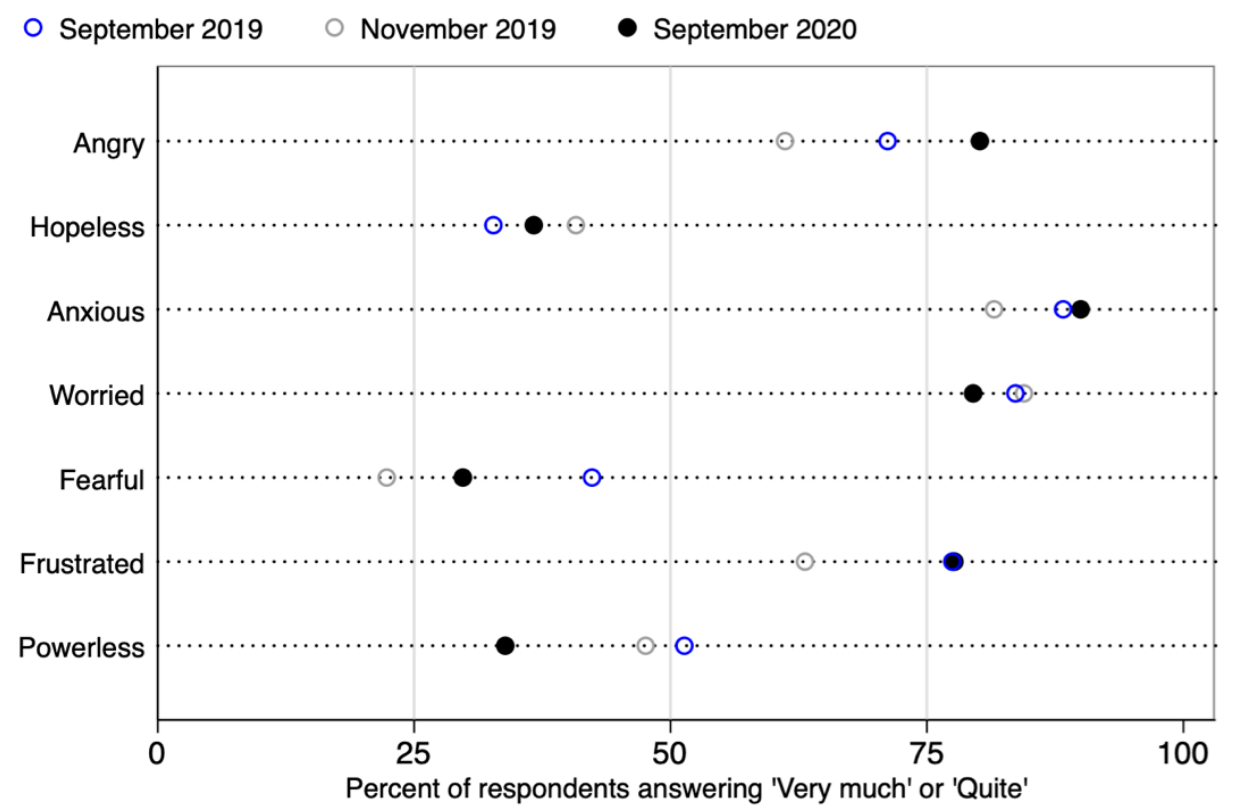

The cognate emotions of anxiety and worry are dominant in almost every survey wave (over $80 \%$ of protesters on average). In September 2020, $90 \%$ of respondents reported feeling "quite" or "very" anxious. Similarly, $80 \%$ reported feeling worried. After anxiety-worry, anger and frustration are the next most dominant emotions. The pattern of greater feelings of anger over time is very similar to that described for anxiety. Although majorities of respondents reported feelings of anger and frustration at all three events, anger reached a new peak at the September 2020 GCS in pandemic contexts. At this event, anger was slightly more prominent than frustration among protesters ( $80 \%$ anger, $78 \%$ frustration).

Feelings of powerlessness also declined substantially at the September 2020 GCS. Fewer protesters agreed with feeling "very" or "quite" powerless when thinking about climate change $-14 \%$ less than on average than in November 2019, and 17\% less than in September 2019. As Figure 5.5 shows, generational differences nearly disappeared among protesters in pandemic contexts, as with majorities reported feeling "somewhat" powerless.

Figure 5.5: Powerlessness

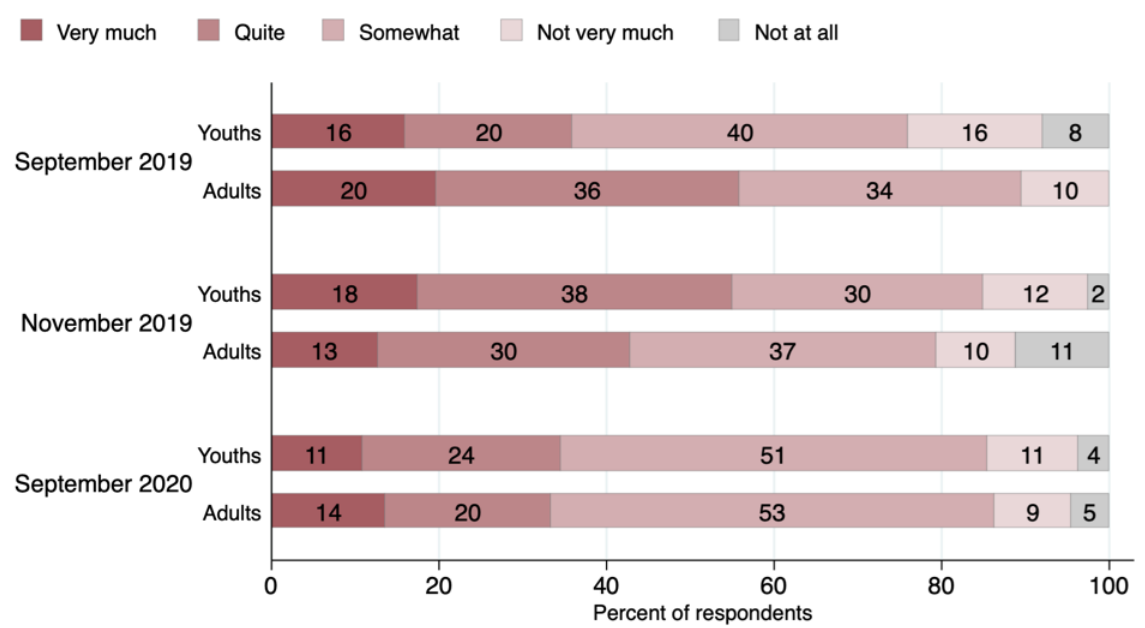


Supporting this trend are responses to a question on whether the respondent "feel[s] hopeful about policies being able to address climate change" (see Figure 5.6). The share of protesters that reported feeling hopeful reached a majority $(60 \%)$ at the GCS in pandemic contexts. FFF protesters' greater sense of hope is largely in line with the reduction in feelings of powerlessness and the strengthening efficacy perceptions.

Figure 5.6: Hopeful That Policies Can Address Climate Change

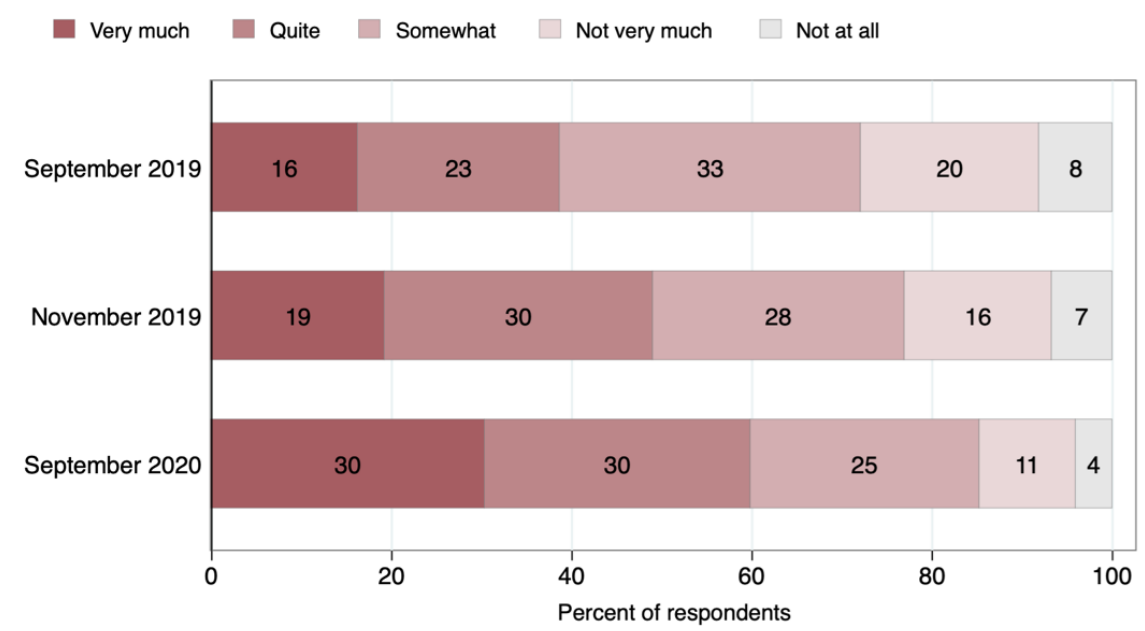

Overall, protesters at the September 2020 GCS were highly motivated to participate for multiple reasons, including greater confidence in the ability of their actions to have an impact. Widespread feelings of anger and anxiety when thinking about climate change as well as hope in the ability of policies to address climate change are likely to have amplified these motivations.

\section{$6 \quad$ Who can be trusted to address the climate crisis?}

From our previous survey work (and section 4 of this report), we know that participants at GCS events in Berlin are highly politically engaged despite low levels of confidence in traditional political institutions (c.f. Gardner \& Neuber 2020; Neuber \& Gardner 2020). This combination of political engagement and skepticism towards powerholders is apparent from results on items asking protesters about the types of institutions they think can be relied on to address the myriad problems stemming from the climate crisis. At the September 2020 GCS in pandemic contexts, FFF protesters' ranking of different actors and institutions on their reliability to address climate problems was consistent with our pre-pandemic GCS survey results: with the most faith in modern science, followed by limited support for the primacy of individual lifestyle changes, then government institutions, and companies/the market last. ${ }^{11}$

Although the largest shares of protesters identified modern science as the most reliable force for change at every event, the extent of agreement with the statement "modern science can be relied on to solve our environmental problems" intensified among both youth and adult participants at the September 2020 GCS. As Figure 6.1 shows, belief in modern science was highest among adult and youth protesters at the GCS in pandemic contexts. The strength of agreement was also highest among both cohorts at this event ( $27 \%$ and $30 \%$ respectively).

\footnotetext{
${ }^{11}$ Also consistent with our previous findings, youth respondents are generally a bit more optimistic than adults about relying on different institutions to curb climate change.
} 
Figure 6.1: Rely on Modern Science

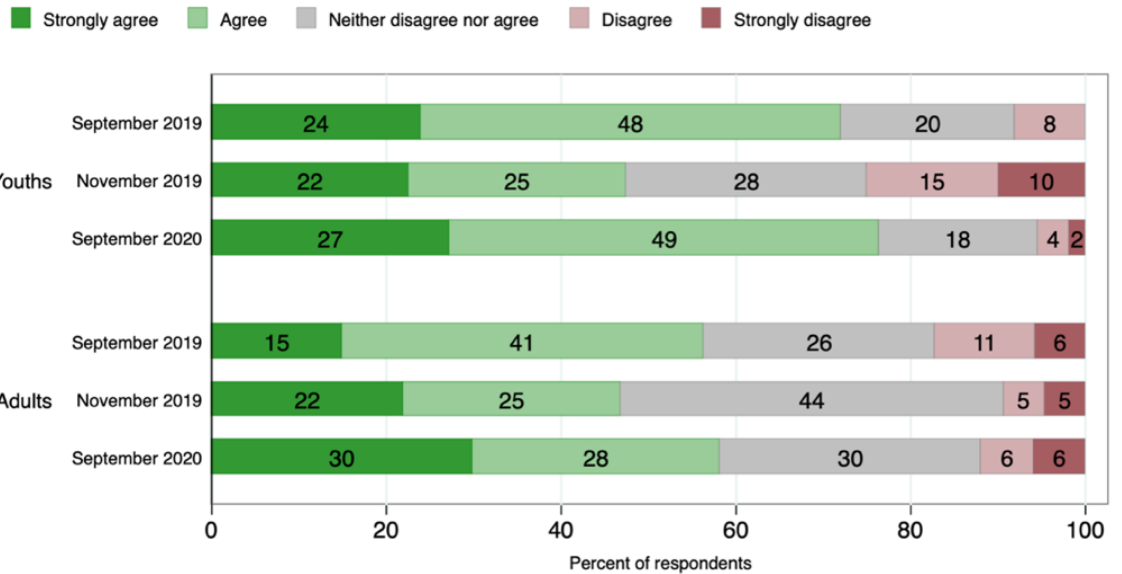

As previously mentioned, belief in the efficacy of voluntary, individual lifestyle change as a means to halting climate change consistently falls somewhere in the middle between majorities for modern science and low levels of confidence in governments and companies. Support for the idea that stopping climate change "can primarily be accomplished through voluntary lifestyle changes" remained low at the September 2020 GCS. Average protester agreement with this approach went from 36\% at the September 2019 GCS to $25 \%$ in November 2019, and $24 \%$ at the pandemic GCS (not shown).

As Figure 6.2 illustrates, the trend of decreasing support for lifestyle approaches over time is primarily driven by younger participants. However, the generational difference was marginal at the September GCS in pandemic contexts. At this event, the largest shares of protesters were ambivalent ( $\sim 40 \%$ of youth and adults). These results, along with the privileging of scientific expertise, reinforce arguments that FFF participants believe change must primarily occur at the policy level (c.f. Gardner \& Neuber 2020).

Figure 6.2 Voluntary Lifestyle Change

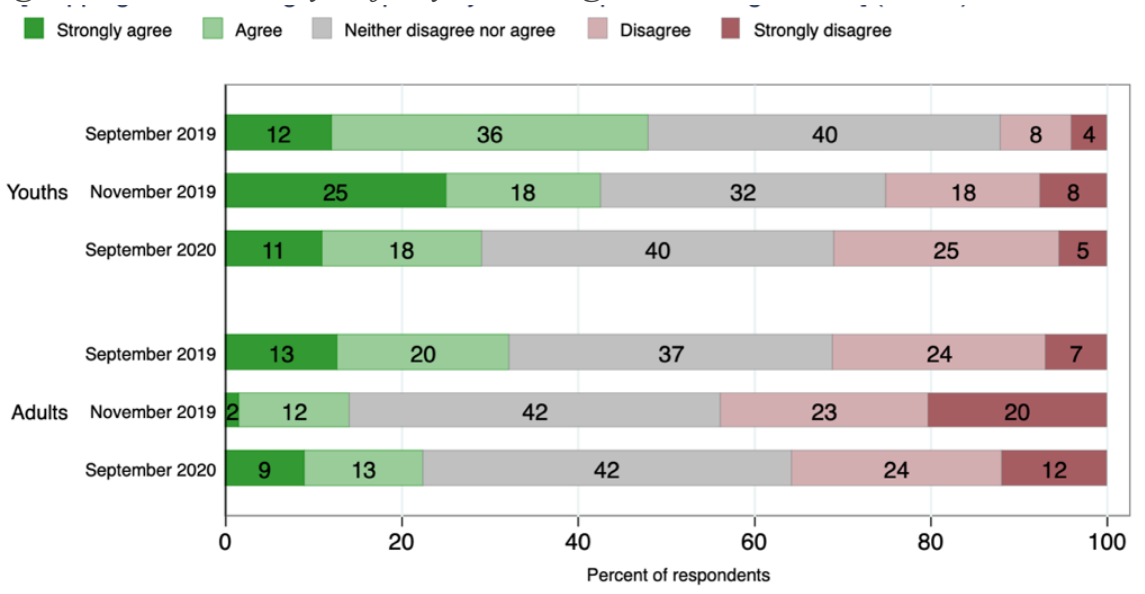

FFF protesters' perceptions of party politics and politicians provide additional support for this assertion. As Figure 6.3 shows, very small minorities of protesters 'strongly agreed' or agreed' that 'I don't see the point of voting, parties do what they want anyway.' At the pandemic GCS, $93 \%$ of participants disagreed with the statement. The shares of participants that think parties are accountable to their voting base or that voting directs the actions of political parties increased over the three GCS demonstrations for both age cohorts (cohort results not shown). 
Figure 6.3: Accountability of Political Parties

[I don't see the use of voting, parties do whatever they want anyway.]

$\square$ Strongly agree $\square$ Agree $\square$ Neither $\square$ Disagree $\square$ Strongly disagree

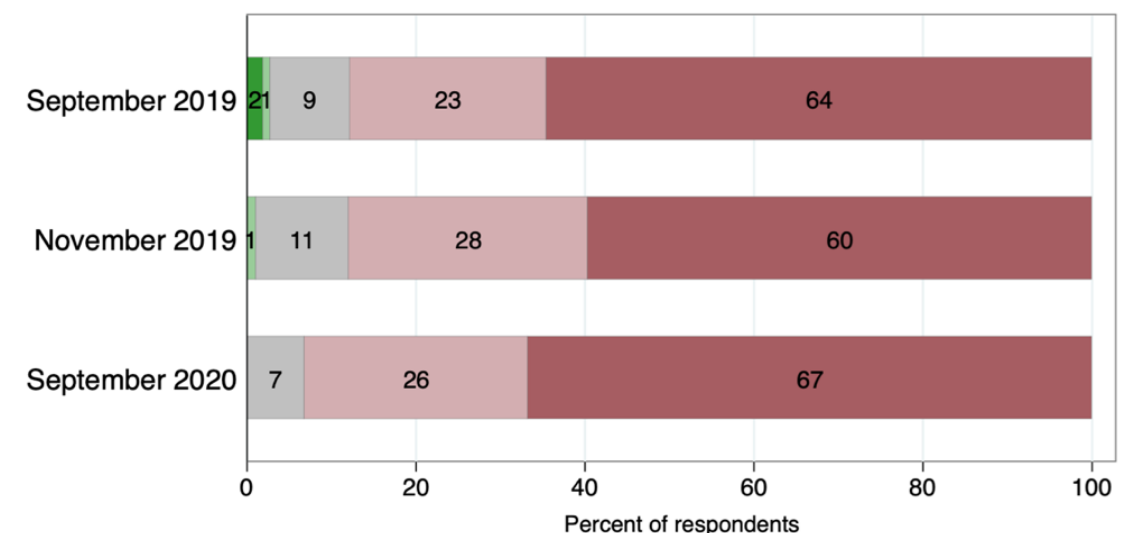

Similarly, although FFF protesters are skeptical of politicians, skepticism declined slightly among respondents at each event surveyed (see Figure 6.4). Ambivalence in the ability of politicians to fulfill their promises increased, especially among adult respondents (not shown). These results for parties and political promises suggest GCS participants don't think elected officials do whatever they want or that their policy-making doesn't matter. They also hint at the possibility that political responses to the Covid-19 pandemic helped to reduce disaffection with German politics. Results for trust in governing institutions lend additional weight to this interpretation.

Figure 6.4: Politicians Make Empty Promises

[Most politicians make a lot of promises but do not actually do anything.]

Strongly agree $\square$ Agree $\square$ Neither $\square$ Disagree $\square$ Strongly disagree

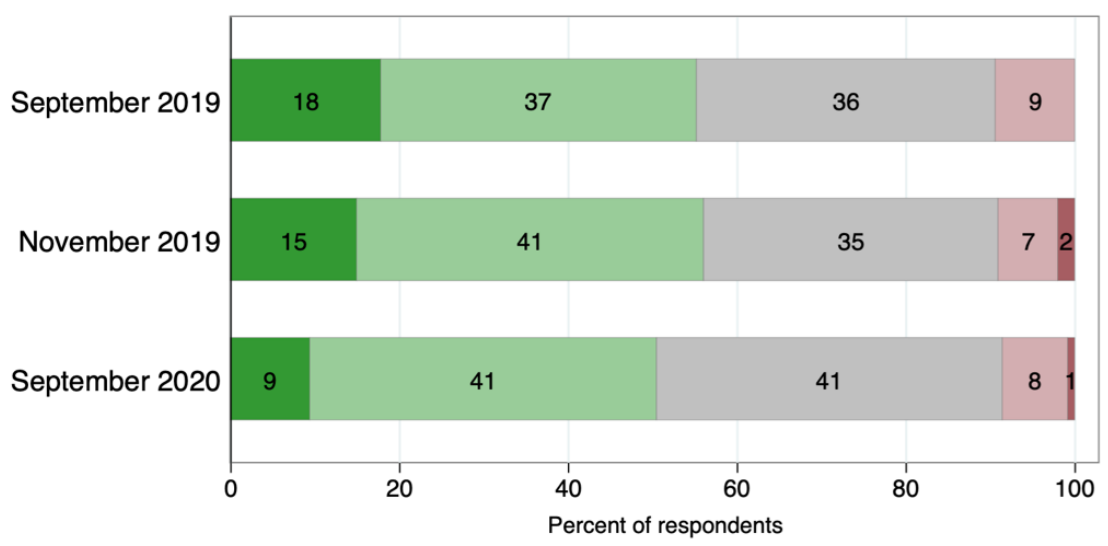

Respondents were asked about their trust in various institutions. Unlike the consistent ranking in the confidence questions discussed earlier, the ranking on trust in institutions changed at the GCS in pandemic contexts. Results from the GCS surveys in September 2020 point to a large increase in trust in national parliaments and governments. Before the pandemic, international governing bodies (the EU and the UN) were the most trusted political institutions among participants, followed by national governing bodies (e.g. parliament), and then political parties (c.f., Neuber \& Gardner 2020; Sommer et al. 2020). At the GCS in pandemic contexts, levels of trust in national government exceeded those for the EU, where trust levels declined slightly. As Figure 6.5 shows, a majority of protesters at the September 2020 GCS expressed trust in the national government for the first time. These shifts may reflect Germany's relative success in limiting the number of COVID-related deaths compared to other countries in the first wave 
of the pandemic. They are also in line with other studies pointing to a renewal of trust in established political institutions in the wake of the pandemic (e.g., Schumacher \& Fagan 2020; Vehrkamp \& Merkel 2020).

\section{Figure 6.5: Trust in National Government \& Trust in the European Union}

very much $\square$ quite $\square$ somewhat $\square$ not very $\square$ not at all

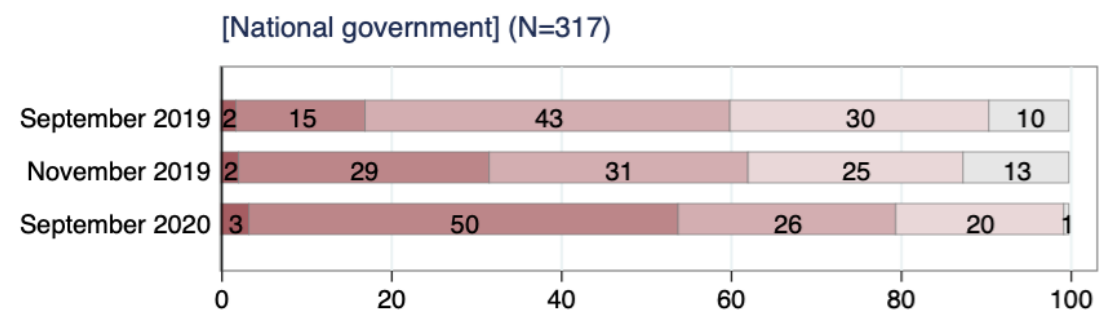

[European Union] $(\mathrm{N}=320)$

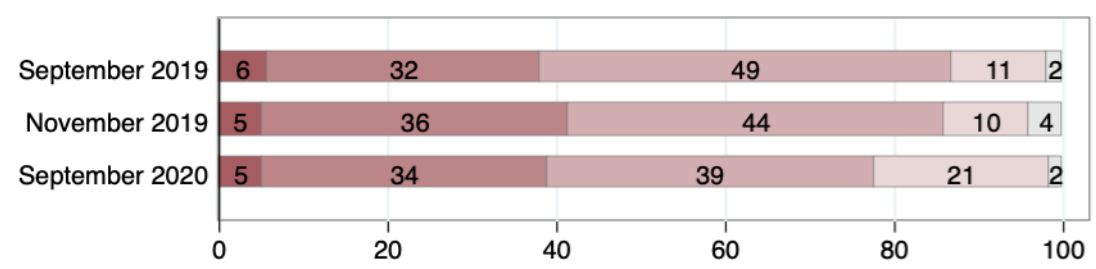

Finally, FFF protesters' negative perceptions of companies and the market intensified at the GCS in pandemic contexts. As Figure 6.6 shows, large majorities of GCS participants 'strongly disagree' or 'disagree' that 'companies and the market can be relied on to solve our environmental problems.' Notably, this is one of the most strongly held beliefs compared to other items. With the marginal exception of youth protesters at the September 2019 GCS (not shown), a clear majority of protesters at every GCS examined here strongly disagreed with the statement. $^{12}$

Figure 6.6: Rely on Companies and the Market

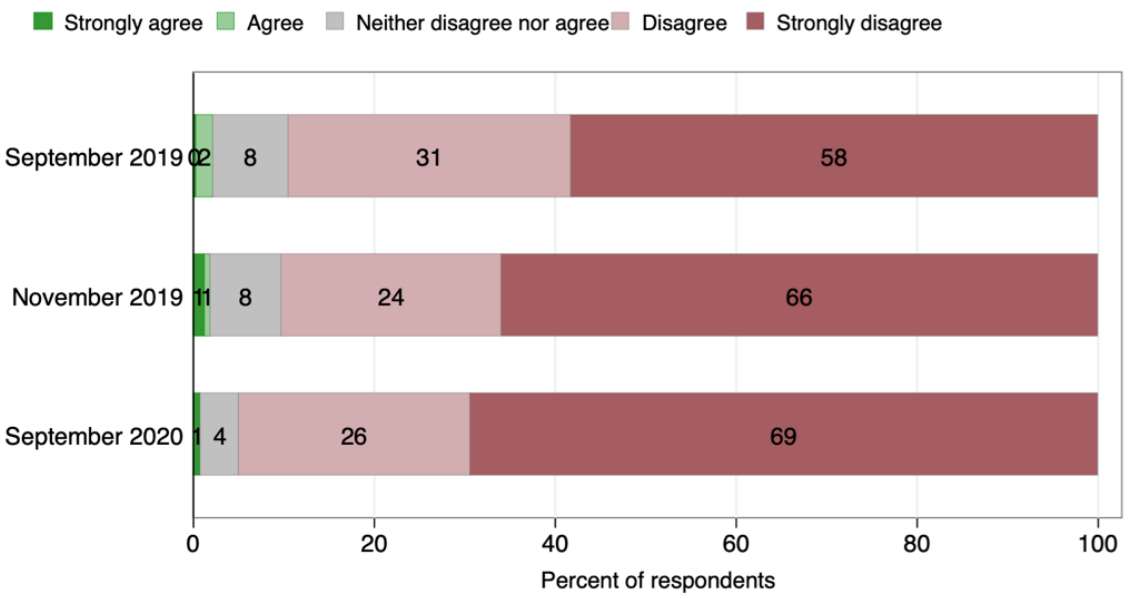

\footnotetext{
${ }^{12}$ Respondents at the September 2020 GCS were also asked about their trust in corporations or business groups in general. On this item, over $70 \%$ of youths and adults expressed little to no trust.
} 


\section{$7 \quad$ Protesting in pandemic contexts}

For the September 2020 GCS, we introduced a handful of new questions specifically about pandemic-related concerns. Among them, respondents were asked an open-ended question about the impact of the pandemic on their decision to participate in the protest. We coded answers and clustered them into four general categories of influence: encouraged, no influence, ambivalent, and discouraged. Overall, the majority of respondents said the pandemic did not influence their participation decision.

Figure 7.1, which presents the results by generational cohort, suggests that the pandemic had a bigger impact on the decision-making of younger protesters. Larger proportions of youths than adults reported that the pandemic encouraged their participation, discouraged it, or made them feel ambivalent about joining the protest (i.e., pushed them in two directions). However, the patterns across the general response categories are similar among both cohorts. For instance, a larger share of both youth and adult protesters reported that the pandemic encouraged their participation than discouraged it.

Figure 7.1: Influence of the Pandemic on Decision to Protest

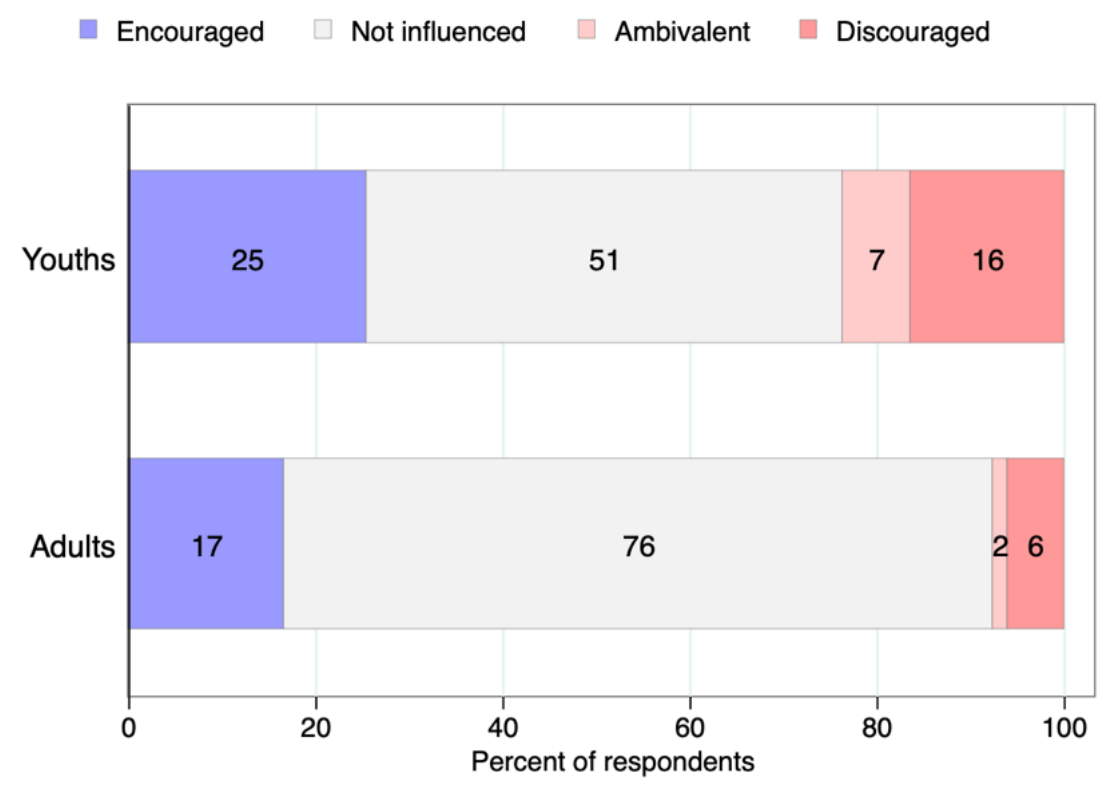

A closer examination of the open-ended responses offers some additional nuance to these results. With respect to overcoming potential barriers to participation in pandemic contexts, we identified two main patterns among respondents. The first concerns FFF organizers' capacity to offset pandemic risks by encouraging and closely adhering to safety precautions. About one in four demonstrators stated that trust in the organizers and their hygiene concept and/or confidence in the consideration of fellow demonstrators played an important role in their decision-making. The second concerns the incentive of recouping attention to the climate crisis that was lost by the pandemic. For example, protesters commonly stated that waning public attention to the issue of climate change due to the pandemic motivated their activism (echoing the widely held motive to raise awareness shown in section 5). Several respondents also cited participation in the GCS as a form of counter-mobilization or consciousness-raising against the wave of so-called anti-lockdown or Corona protests. 
Related to the second response pattern of raising attention for the climate crisis, another new question asked demonstrators about their views on prioritizing the pandemic "even if it slows down progress on climate change." While minorities of respondents believed the pandemic should be the priority, the differences between the two age cohorts were stark (see Figure 7.2). Majorities (68\%) of adult protesters 'disagreed' or 'strongly disagreed' with prioritizing the Covid-19 pandemic, as compared to only $35 \%$ of youths. The largest share of youth protesters expressed ambivalence (44\%). On the opposite end of the spectrum, only $5 \%$ of adults as compared to $20 \%$ of youths agreed with putting the pandemic ahead of climate change.

\section{Figure 7.2: Prioritize the Pandemic Over Climate Change}

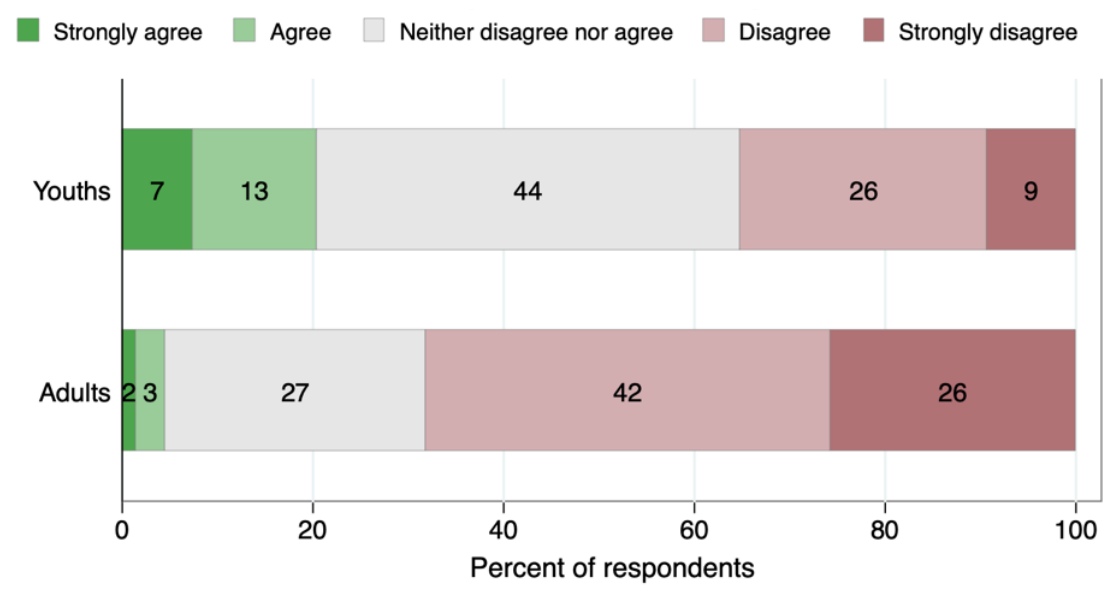

Of final note, according to newly introduced questions concerning perceptions about the official measures to prevent the spread of Covid-19 (e.g., obligation to wear masks, travel restrictions, quarantine protocols), FFF protesters were resoundingly supportive. Over $90 \%$ of respondents in both generational cohorts thought such measures were appropriate, and clear majorities of both groups strongly supported current obligations (results not shown). These results coincide with our observations of protesters' adherence to social distancing and mask requirements on the day of the event.

\section{Conclusion}

Drawing on new survey data on protesters at the September 2020 Global Climate Strike in Berlin, this study examines how the profile of Fridays for Future (FFF) protesters shifted after the onset of the Covid-19 pandemic. Our results broadly show the protesters mobilized in pandemic contexts were somewhat younger, more politically engaged, more motivated, and more trusting in German politics than those at pre-pandemic GCS in September and November of 2019. Results on protesters' emotions and perceptions about the pandemic cut across these findings. They indicate that most protesters took the pandemic seriously, but did not let it discourage their participation and did not think it should eclipse climate change issues. Moreover, they suggest that FFF protesters saw the pandemic contexts as both a political opportunity and a threat to policy movement on effectively addressing climate change. In what follows, we elaborate on these general interpretations of the results.

Our socio-demographic comparison of participants at the three GCS events in Berlin points to the movement's evolving composition. In pandemic contexts, the average protester age declined significantly (from 36 in November and September of 2019 to 31 in September of $2020 ; p<.05)$, but the profile was still far from a return to first ever GCS in March of 2019 
where pupils and youths 25 -years or younger made up the majority of participants. Instead, we find a broader type of youth movement, with a high percentage of university students and young professionals joining the street demonstration. In our view, the partial 'rejuvenation' of FFF protesters at the September 2020 GCS not only reflects the movement's ongoing leadership and support base of young people but can also be linked to the heightened risks and care burdens the Covid-19 pandemic posed to older age groups. In other words, we find what may be likened to a shifting "biographical availability" structural under pandemic conditions (McAdam 1982).

The political engagement profile of FFF protesters at the GCS in pandemic contexts also shifted in some marked ways. Our results on past protest experience, political behaviors, and depth of organizational involvement suggest that the people who joined the GCS on September 252020 were more politically active and institutionally embedded than those at prior GCS events. While the proportion of respondents with prior protest experience was high, including experience at previous GCS events, there were still a handful of first-time protesters and firsttime GCS participants. This suggests that being among the already committed was not the only key driver of participation.

Dovetailing with the political commitment of protesters, we found FFF protesters at the September 2020 GCS stood out for their strong consensus on multiple motivation questions. Notably, respondents were much more motivated to participate in the pandemic GCS to raise public awareness than at the previous two events. Perceptions of personal and collective efficacy - beliefs that political engagement can bring about change-also increased and reached a new level of consensus among youths and adults. Complimenting these results, we found notable shifts in a combination of emotions that are likely to have amplified people's motivations for protesting: FFF protesters were angrier and anxious when thinking about climate change, but they also felt less powerless, and they felt more hopeful about the potential for policy to address climate change. These results suggest that the pandemic didn't simply bring out the more persistent committed but influenced the constellation of motivations spurring FFF supporters to protest, including assessments of institutional arrangements.

Measures capturing FFF protesters' confidence and trust in political institutions suggest their views about potential allies in the fight against climate change or institutional allegiances were impacted by the pandemic. Beyond intensified trust in science, politicians, political parties, and national government all came to be perceived more positively at the GCS in pandemic contexts. Of particular note, a majority of FFF protesters expressed trust in the national government for the first time at the September 2020 GCS (53\%). With these new levels of trust, the German government came to replace the EU as one of the most trusted political institutions (39\%).

Responses on newly introduced survey items about the pandemic add additional nuance to these results and suggest the pandemic played a galvanizing role. For example, respondents' overwhelming support of official measures to curtail the spread of Covid-19 in Germany helps to account for the rise in political confidence. However, this is not to say that FFF protesters perceived political developments in the wake of Covid-19 as uniformly "good" or "bad." Instead, there appears to be tentative optimism amidst confidence in the German government's response to the pandemic crisis on the one hand (opportunity), and dissatisfaction with attention or political awareness shifting away from the ongoing climate crisis on the other (threat). That is, the pandemic contexts generated greater confidence in obtaining an effective, scientificallybased policy response to the climate crisis and also spurred activists to endeavor to regain the attention to climate change that was siphoned off by the pandemic. 
Supporting this interpretation, we found younger FFF protesters expressed uncertainty about how to best address the compounding threats of pandemic and climate crisis, whereas a majority of adults viewed the sidelining of climate change in addressing the pandemic as unacceptable. We also suspect that such mixed results reflect the thorniness of addressing these interconnected issues. To be sure, the speedy, scientifically-informed, and largely effective government actions in response to the Covid-19 pandemic contrasts with the backdrop of slowpaced and limited action on climate change. This may fuel dissonance between perceptions that the state is capable of enforcing science-based regulations in crisis scenarios and concerns that they will not be applied to the climate crisis - or worse, that efforts to recover from the pandemic will permit additional environmental degradation and undermine movement goals. In the leadup to the upcoming national elections in Germany, the FFF movement's mobilization efforts to raise public awareness about climate policy issues and to pressure German politicians to take concrete and effective action on climate change seem more important than ever. 


\section{References}

Almeida, P. (2019). Climate justice and sustained transnational mobilization. Globalizations 16: $973-979$.

Chase-Dunn, C., \& Almeida, P. (2020). Global Struggles and Social Change: From Prehistory to World Revolution in the Twenty-First Century. Johns Hopkins University Press.

Collins, R. (2004). Interaction ritual chains. Princeton University Press.

de Moor, J., De Vydt, M., Uba, K., \& Wahlström, M. (2020a). New kids on the block: taking stock of the recent cycle of climate activism. Social Movement Studies, 1-7.

de Moor, J., Katrin, U., Wahlström, M., Wennerhag, M., De Vydt, M. (Eds.) (2020b). "Protest for a future II: Composition, mobilization and motives of the participants in Fridays For Future climate protests on 20-27 September, 2019, in 19 cities around the world." Online: https://osf.io/asruw/, accessed on August 10, 2020.

Dimok, M. (2019). "Defining generations: Where Millennials end and Generation Z begins." Pew Research Center. Retrieved from: https://www.pewresearch.org/facttank/2019/01/17/where-millennials-end-and-generation-z-begins/, accessed on May, 152021.

Fisher, D.R., Andrews, K.T., Caren, N., Chenoweth, E., Heaney, M.T., Leung, T., Perkins, L.N., Pressman, J. (2019). The science of contemporary street protest: New efforts in the United States. Science Advances, 5(10), eaaw5461.

Gardner, B.G., \& Neuber, M. (2020). Climate justice in a populist era: Grievance politicization among Fridays for Future protesters in Germany. In: Schäfer, A., Meiering, D. (Eds.), (Ent)Politisierung? Die demokratische Gesellschaft im 21. Jahrhundert. Leviathan Sonderband 35. Baden-Baden: Nomos, pp. 173-204.

Goodwin, J., Jasper, J. M., \& Polletta, F. (Eds.). (2009). Passionate politics: Emotions and social movements. University of Chicago Press.

Inglehart, Ronald 1977. The Silent Revolution. Princeton, NJ: Princeton University Press.

Jasper, J. M. (2014). Constructing indignation: Anger dynamics in protest movements. Emotion Review, 6(3), 208-213.

Klandermans, B., Van der Toorn, J., \& Van Stekelenburg, J. (2008). Embeddedness and identity: How immigrants turn grievances into action. American Sociological Review, 73(6), 992-1012.

McAdam, D. (1986). Recruitment to high-risk activism: The case of freedom summer. American Journal of Sociology, 92(1), 64-90.

McAdam, D. (1988). Freedom summer. Oxford University Press, USA.

Metternich, N. W. (2020). Drawback before the wave?: Protest decline during the Covid-19 pandemic. Online preprint: https://osf.io/preprints/socarxiv/3ej72/ 
Milkman, R. (2017). A new political generation: Millennials and the post-2008 wave of protest. American Sociological Review, 82(1): 1-31.

Neuber, M., (2021). Who kept the climate movement moving during Covid-19? A short analysis of reported protest activities between August 2018 and April 2021. Research Blog, https://michael-neuber.com/research-blog/, accessed on June 7, 2021.

Neuber, M., Gardner, B.G. (2020). Germany. In: Protest for a Future II : Composition, Mobilization and Motives of the Participants in Fridays For Future Climate Protests on 20-27 September, 2019, in 19 Cities around the World. pp. 117-138.

Neuber, M., Kocyba, P., Gardner, B.G. (2020). The same, only different: Die Fridays for Future-Demonstrierenden im europäischen Vergleich. In: Haunss, S., Sommer, M. (Eds.), Fridays for Future - Die Jugend gegen den Klimawandel. Konturen der weltweiten Protestbewegung. transcript, Bielefeld, pp. 67-94.

Saunders, C., Grasso, M., Olcese, C., Rainsford, E., \& Rootes, C. (2012). Explaining differential protest participation: Novices, returners, repeaters, and stalwarts. Mobilization: An International Quarterly, 17(3), 263-280.

Schumacher, S. \& M. Fagan. (2020). Confidence in Merkel is at all-time high in several countries during her last full year in office. Retrieved from: https://pewrsr.ch/33mlb $7 \mathrm{~b}$, accessed on May 15, 2021.

Shultziner, D. (2013). The social-psychological origins of the Montgomery bus boycott: social interaction and humiliation in the emergence of social movements. Mobilization: an International Quarterly, 18(2), pp. 117-142.

Sommer, M., Haunss, S., Gardner, B.G., Neuber, M., Rucht, D. (2020). Wer demonstriert da? Ergebnisse von Befragungen bei Großprotesten von Fridays for Future in Deutschland im März und November 2019. In: Haunss, S., Sommer, M. (Eds.), Fridays for Future - Die Jugend gegen den Klimawandel. Konturen der weltweiten Protestbewegung. transcript, Bielefeld, pp. 15-66.

TAZ (2019): "Fridays for Future" Bewegung. Zukunft nicht nur für die Elite. M'Barek, Yasmine TAZ, 17.04.2019, https://taz.de/Fridays-for-Future-Bewegung/!5589135/, accessed on December 13, 2019.

Thunberg, G. (2019). No One Is Too Small to Make a Difference: Illustrated Edition. Penguin UK.

Van Aelst, P., Walgrave, S., 2001. Who is that (wo)man in the street? From the normalisation of protest to the normalisation of the protester. Eur J Political Res 39, 461-486.

Van Stekelenburg, J., \& Klandermans, B. (2013). The social psychology of protest. Current Sociology, 61(5-6), 886-905.

Van Stekelenburg, J., Walgrave, S., Klandermans, B., \& Verhulst, J. (2012). Contextualizing contestation: Framework, design, and data. Mobilization: An International Quarterly, 17(3), 249-262. 
Vehrkamp, R. \& W. Merkel. (2020). Populism Barometer 2020: Populist attitudes among voters and non-voters in Germany (Bertelsmann Stiftung 2020), https://www.bertelsmannstiftung.de/fileadmin/files/BSt/Publikationen/GrauePublikationen/ZD_Studie Populismusbar ometer_2020.pdf, accessed on May 15, 2021.

Voelkle, M.C., Ebner, N.C., Lindenberger, U., Riediger, M. (2012). Let me guess how old you are: Effects of age, gender, and facial expression on perceptions of age. Psychology and Aging $27,265-277$.

Wahlström, M., Kocyba, P., De Vydt, M., de Moor, J. (Eds.) (2019). "Protest for a future: Composition, mobilization and motives of the participants in Fridays For Future climate protests on 15 March, 2019 in 13 European cities." Online: https://osf.io/xcnzh/, accessed on January 26, 2020.

Walgrave, S., Wouters, R., Ketelaars, P. (2016). Response Problems in the Protest Survey Design: Evidence from Fifty-One Protest Events in Seven Countries*. Mobilization: An International Quarterly 21, 83-104. 